\title{
RECONOCIMIENTO Y EJECUCION EN ALEMANIA DE SENTENCIAS EXTRANJERAS DE DAÑOS PUNITIVOS Comentario a la decisión del Tribunal Federal de Justicia alemán (Bundesgerichtshof), de 4 de junio de 1992
}

\author{
Goretti Vadillo Robredo
}

\begin{abstract}
Sumario: I. Introducción. II. Marco legal para el reconocimiento y la ejecución de sentencias en Alemania. 1. General. 2. Reconocimiento de una sentencia indemnizatoria de daños y perjuicios de los Estados Unidos, art. 328(1) del ZPO. 3. Decisiones alemanas. III. Daños punitivos. 1. Definición. 2. Naturaleza de la indemnización. 3. Daños punitivos v. Orden público alemán. a) Posturas a favor. b) Posturas en contra. IV. Comentario a la decisión del Tribunal Federal de Justicia Alemán (Bundesgerichtshof), de 4 de junio de 1992. 1. Los hechos. 2. «Pre-trial Discovery». 3. «Contingent fee». 4. Indemnización económica excesiva bajo los criterios del país. 5. Daños punitivos. 6. Reconocimiento parcial. V. Conclusión.
\end{abstract}

\section{Introducción}

La indemnización de daños punitivos es, probablemente, una de las figuras del Derecho anglosajón que más curiosidad despierta para un jurista continental ${ }^{1}$.A partir de la década de los ochenta, se ha pasado

1 Un ejemplo de indemnización de daños punitivos que atrajo la atención del público norteamericano fue la del Tribunal Supremo de Missouri, en el que se anuló un veredicto de 40 millones de dólares (de los cuales 20 millones correspondían a daños punitivos). Esta indemnización se había concedido a una mujer que sufre de parálisis como consecuencia de un accidente de automóvil, ocurrido en febrero de 1990. Ese mismo año, un jurado del Circuit Court de St. Louis indemnizó a la Sra. Rodríguez con 30 millones de dólares como indemnización compensatoria y 60 millones de dólares por daños punitivos. El demandado era Suzuki Motor Corp. En la apelación entablada por Suzuki, la Juez Anna C. Forder redujo la indemnización a 20 millones como daños compensatorios y 20 millones como daños punitivos. El Tribunal Supremo devolvió el caso al Tribunal de St. Louis para un nuevo juicio. 
de la mera curiosidad doctrinal hacia la figura de los daños punitivos a la necesidad de que algunos órganos jurisdiccionales deban examinar la figura. En primer lugar, Tribunales europeos se han visto obligados a tratar esta cuestión en el ámbito de su notificación en el contexto del Convenio de La Haya, de 25 de octubre de 1965². En segundo lugar, los órganos jurisdiccionales europeos, especialmente los de Alemania y Suiza, han estudiado los daños punitivos a fin de otorgar o denegar el reconocimiento y la ejecución de una sentencia norteamericana que contuviese dicha partida indemnizatoria.

Las indemnizaciones de daños punitivos siempre han sido objeto de debate en los Estados Unidos, pero en los últimos treinta años la polémica ha crecido, saliendo de los ámbitos jurídicos y llegando al público en general. Además, la figura ha sido objeto de reformas legislativas en el ámbito estatal, y de una Propuesta de Ley federal para limitar su cuantía en un techo superior (en la propuesta actual, vetada por el Presidente Bill Clinton, el límite es de 250.000 dólares o el doble de la cantidad concedida como daños compensatorios ${ }^{3}$ ).

El debate ha entrado en Europa en relación con la ejecución de sentencias norteamericanas en las que se contiene la partida de daños punitivos. En concreto, la cuestión se ha planteado en Alemania, Suiza y también en Japón. El sistema jurídico alemán es el que se ha visto obligado a responder a un mayor número de cuestiones relativas a los daños punitivos ${ }^{4}$.

2 En el presente artículo no vamos a tratar los problemas planteados en el contexto de la notificación, puesto que queda fuera de los límites del presente estudio (sobre esta cuestión véase Requejo Isidro, M., «Punitive Damages y su notificación en el contexto del Convenio de La Haya de 15 de octubre de 1965», Revista Española de Derecho Internacional, vol. XLVIII, 1996, n. ${ }^{\circ} 2$, pp. 71 y ss. y «Germany: Federal Constitutional Court Orders concerning Service of Punitive Damage Claims», International Legal Materials, vol. XXXIV, 1995, pp. 975 y ss.).

3 Secc 1033. Product Liability Reform

(c) Limitations on Punitive Damages:

(1) General limitation: Punitive damages may, to the extent permitted by applicable State law, be awarded against a manufacturer or product seller in a product liability action if the claimant establishes by clear and convincing evidence that the harm suffered was the result of conduct manifesting actual melice.

(2) Limitation on amount: The amount of punitive damages that muy be awarded for a claim in any civil action subject to this section shall not exceed 3 times the amount awarded to the claimant for the economic injury on which such claim is based, or $\$ 250,000$, whichever is greater.

4 Vid. Requejo Isidro, M., «Punitive Damages y su notificación...», loc. cit., p. 72, en donde la autora pone de relieve que «es el alemán el sistema jurídico más afectado por la cuestión, lo que a todas luces se justifica en el volumen y envergadura de las relaciones comerciales entre EEUU y la RFA; pero evidentemente no quedan excluidos planteamientos semejantes en otros países europeos, entre los que se cuenta España».

Hasta el momento no existe ninguna decisión de Tribunales españoles sobre este tema. 
A continuación, analizaremos el sistema legal alemán de reconocimiento y ejecución de sentencias, la figura de los daños punitivos y comentaremos la sentencia del Tribunal Federal de Justicia de Alemania, de 4 de junio de 1992, en la que se niega la ejecución de una indemnización punitiva.

\section{Marco legal para el reconocimiento y la ejecución de sentencias en Alemania}

\section{General}

El marco legal dentro del que se estudia el reconocimiento de sentencias extranjeras en Alemania está diseñado en los acuerdos bilaterales y multilaterales de los que forma parte Alemania ${ }^{5}$, y también en las normas del Ordenamiento jurídico alemán para aquellas sentencias que provengan de países con los que no hay convenio. Las normas sobre reconocimiento y ejecución de sentencias en materia civil y mercantil se encuentran en el Código de Procedimiento civil (Zivilprozeßordnung; ZPO). El artículo 328 del ZPO trata del reconocimiento en general ${ }^{6}$, mientras que los artículos 722 y 723 del ZPO regulan el procedimiento para la ejecución de las sentencias extranjeras ${ }^{7}$. También debe tenerse en cuenta la Constitución alemana en el reconocimiento y ejecución de

5 Por ejemplo, el Convenio de Bruselas relativo a la competencia judicial y a la ejecución de resoluciones judiciales en materia civil y mercantil (27/9/1968) y la Convención de Lugano ((1988) Official Journal of the European Communities, No. L 319/1).

${ }^{6}$ El Código de Procedimiento civil de Alemania (ZPO), en la sección 328 recoge que no se reconocerán en Alemania las sentencias extranjeras:

a) si los tribunales del país extranjero que emitieron la sentencia no tenían jurisdicción (según la ley de conflictos alemana);

b) si la demanda no fue notificada apropiadamente al demandado, impidiendo por tanto su defensa (328(1) No. 2);

c) si la sentencia extranjera duplica una sentencia alemana o extranjera ya existente, o procedimientos que ya han comenzado y son anteriores a los de la sentencia extranjera (328(1) No. 3);

d) si el reconocimiento de la sentencia da lugar a un resultado incompatible con los principios básicos del Derecho alemán, en particular con los derechos constitucionales (328(1) No. 4);

e) si no hay garantía de reciprocidad (328(1) No. 5).

${ }^{7}$ La Ley de reforma del Derecho privado internacional, de 25 de julio de 1986, trató principalmente cuestiones de derecho sustantivo y no introdujo cambios fundamentales ni adaptó soluciones totalmente nuevas en este tema, aunque los números 2, 3 y 4 del 328(1) sufrieron una nueva formulación. 
sentencias extranjeras ${ }^{8}$. Asimismo, no existe convenio entre Alemania y los Estados Unidos, por lo que para el reconocimiento de las sentencias que provengan de dicho país serán de aplicación los artículos anteriores del $\mathrm{ZPO}^{9}$.

De acuerdo con el 723 II 2 ZPO, no se llevará a cabo la ejecución de una sentencia extranjera si su reconocimiento no es posible según el 328(1) ZPO. Este artículo (el 328(1) del ZPO) contiene una lista de 5 razones por las que se puede negar la ejecución: 1. Cuando el tribunal de origen carece de jurisdicción; 2. Cuando al demandado no le fue adecuadamente notificada la acción; 3. Cuando la sentencia entra en conflicto con una decisión previa sobre la misma cuestión, o es incompatible con una acción previamente iniciada en la República de Alemania; 4. Cuando la sentencia viola nociones fundamentales del orden público alemán; 5. Finalmente, cuando no se asegura la reciprocidad (por ejemplo, cuando una sentencia equivalente alemana no sería ejecutable en el país de origen).

No existe una distinción clara en el 328(1) del ZPO sobre los que son prerrequisitos para el reconocimiento, y los que son defensas en contra del reconocimiento. El artículo 328(1) del ZPO sólo da una lista de bases para negar el reconocimiento. Por lo que la cuestión de la carga de la prueba debe decidirse en cada una de estas cuestiones de forma independiente ${ }^{10}$.

Un requisito inicial para el reconocimiento que no está mencionado explícitamente es que la sentencia extranjera debe ser el resultado de

8 Especialmente desde que el Tribunal Constitucional Federal declaró, en el caso «Spaniar», que las normas de Derecho privado internacional deben ser compatibles con la Constitución alemana (4 de mayo de 1971 Entscheldungen des Bundesverfassungsgerichts BVerfGE 31, $58=$ 1971 NJW 1509 = 36 RabelsZ 45, 141 (1972). La referencia de esta sentencia ha sido tomada de MARTINY, D., «Recognition and Enforcement of Foreign Money Judgments in the Federal Republic of Germany», American Journal of Comparative Law, 1987, vol. 35, pp. 723-724.

${ }^{9}$ Para más información sobre este tema ver: MARTINY, «Recognition and Enforcement...», loc. cit, pp. 721-759; «Kraus, Enforcement of Foreign Money Judgements in the Federal Republic of Germany - Some Aspects of Public Policy», Texas International Law Journal, 1982, vol. 17, pp. 195 y ss.; HAY, P., «The Recognition and Enforcement of American Money-Judgments in Germany - The 1992 Decision of the German Supreme Court», American Journal of Comparative Law, 1992, vol. 40, pp. 729 y ss.; ZeKOLL, J., «Recognition and Enforcement of American Products Liability Awards in the Federal Republic of Germany», American Journal of Comparative Law, 1989, vol. 37, pp. 301 y ss.; STIEFEL, E., StÜrner, R., Stadler, A., «The Enforceability of Excessive U.S. Punitive Damage Awards in Germany», American Journal of Comparative Law, 1991, vol. 39, pp. 779 y ss.; REQUEJo IsIDRo, M., «Reconocimiento en España de sentencias extranjeras condenando al pago de punitive damages», Iniuria, 1995, n. ${ }^{\circ} 6$, pp. 83 y ss.

10 Vid., MartinY, «Recognition and Enforcement...», loc. cit., p. 733. 
un procedimiento civil. Esta ha sido una de las cuestiones que más problemas planteó, en el pasado, a la hora del reconocimiento de las indemnizaciones de daños punitivos, dando lugar a un debate en la doctrina alemana sobre la naturaleza civil o penal de dicha partida indemnizatoria ${ }^{11}$.

Cuatro de los cinco elementos del 328(1) del ZPO no han presentado grandes problemas para el reconocimiento de sentencias norteamericanas de indemnización de daños y perjuicios ${ }^{12}$. El argumento más utilizado en contra del reconocimiento ha sido el 328(1)4 del ZPO, la violación de la sentencia norteamericana del orden público alemán ${ }^{13}$. De acuerdo con el 328(1)4 se niega el reconocimiento sólo en aquellos casos en los que éste produjese un resultado que fuese manifiestamente irreconciliable con los principios básicos esenciales del Derecho alemán, incluyendo los principios constitucionales básicos. El reconocimiento no puede negarse sólo porque el tribunal extranjero aplicó una

11 La naturaleza civil de los daños punitivos es, en la actualidad, aceptada en Alemania de forma casi universal. Esta cuestión se tratará más adelante.

12 Algunas matizaciones sobre el 328(1) ZPO que debemos hacer antes de continuar con la exposición son: en primer lugar, cuando el 328(1) ZPO hace referencia al «tribunal extranjero», se debe interpretar como el cuerpo con autoridad pública que ha sido autorizado bajo la Ley del Estado para resolver disputas sobre materias civiles. En segundo lugar, el término «urteil» (sentencia), en el $328 \mathrm{ZPO}$, se entiende que hace referencia a todas aquellas decisiones que deciden disputas entre partes, independientemente del nombre que reciba la decisión. En tercer lugar, la versión anterior del 328(1)2 discriminaba entre los demandados alemanes y los otros demandados. La nueva versión ya no discrimina a los demandados extranjeros, su texto se ha ajustado al art. 27.2 de la Convención de Bruselas y a las recientes convenciones bilaterales. En cuarto lugar, el 328(1)3 no impide que la sentencia extranjera pueda tratar cuestiones que han sido la cuestión litigiosa en otros tribunales, sino que bajo el 328(1)3 del ZPO una sentencia extranjera que entra en conflicto con una sentencia previa de un tercer Estado y que tiene derecho a reconocimiento en Alemania funciona como forma para impedir el reconocimiento. Está claro que la sentencia extranjera tampoco puede ser reconocida si es incompatible con una decisión previa de un tribunal alemán en una acción entre las mismas partes. La idea básica es que en procesos paralelos la prioridad se le debe dar a la sentencia primera en el tiempo. La regla del «primero en el tiempo» no es discutida. Por último, no existe una definición legal de «reciprocidad» en el 328(1)5 ZPO pero existe una jurisprudencia bien establecida. Es suficiente que la reciprocidad se asegure por el derecho o por la jurisprudencia. Es suficiente que el Estado extranjero esté preparado para reconocer las sentencias extranjeras y no es necesario que todo tipo de sentencias alemanas sean reconocidas en el otro Estado. La reciprocidad es divisible.

13 En España existen dos regímenes de reconocimiento: el de reciprocidad (arts. 952 y 953 de la LEC) y el de condiciones, subsidiario del anterior, art. 954 LEC (aunque, de hecho, se ha convertido en el principal). El punto tercero de este artículo trata la no contrariedad con el orden público español; es decir, que «la obligación para cuyo cumplimiento se haya procedido sea lícita en España». Sobre el reconocimiento en España de daños punitivos vid. REQUEJO ISIDRO, «Reconocimiento en España...», loc. cit., pp. 83 y ss. 
ley que es diferente de las leyes domésticas a menos que sea fundamentalmente incoherente con el sistema legal alemán. El no reconocimiento debe ser la ultima ratio. La razón para este alto nivel de tolerancia está basada en la prohibición de revisión del fondo que deben observar los Tribunales alemanes. Bajo ninguna circunstancia puede examinarse el fondo del asunto de la sentencia extranjera; en otras palabras, no se puede investigar si la decisión del tribunal extranjero fue correcta $^{14}$. El mismo estándar rige para las diferencias procesales que puedan existir entre los dos sistemas. El demandado sólo puede impedir el reconocimiento basado en las diferencias procesales cuando entren en conflicto con los principios legales procesales esenciales del proceso alemán .

\section{Reconocimiento de una sentencia indemnizatoria de daños y perjuicios de los Estados Unidos, artículo 328(1) del ZPO}

Cuando una sentencia norteamericana de indemnización de daños y perjuicios llega a los Tribunales alemanes en busca de su reconocimiento y ejecución se encontrará con una serie de dificultades, tanto si contiene como si no una partida indemnizatoria de daños punitivos. Ciertamente, como hemos apuntado en el apartado anterior, el escollo más importante al que se han enfrentado las decisiones de los órganos judiciales norteamericanos ha sido la violación del orden público alemán que supone una indemnización punitiva, pero éste no ha sido el único. A continuación, vamos a tratar algunas de estas cuestiones, todas ellas en mayor medida solventadas ya por la doctrina y la jurisprudencia alemana, entre las que podemos destacar: diferencias procesales entre los dos sistemas, indemnización de los daños compensatorios (en especial los daños morales), la aplicación del artículo 38 del Título Preliminar del Código civil alemán $(E G B G B)^{15}$ y el pago de honorarios de abogados ${ }^{16}$.

14 El mismo principio se aplica bajo la Convención de Bruselas y bajo otros acuerdos bilaterales.

15 Einführungsgesetz zum Bürgerlichen Gesetzbuch.

16 En la década de los setenta la doctrina alemana también analizó la posible incompatibilidad de las indemnizaciones de daños causadas por productos defectuosos y el orden público alemán, como consecuencia de la teoría de responsabilidad objetiva que era de aplicación en los Estados Unidos. Hoy en día esta cuestión carece de importancia tras la aprobación de la Directiva 85/374/CEE del Consejo, de 25 de julio de 1985, relativa a la aproximación de las disposiciones legales, reglamentarias y administrativas de los Estados miembros en materia de responsabilidad por los daños causados por productos defectuosos. 
1. Ocasionalmente, se ha alegado que las sentencias norteamericanas podrían violar la cláusula de orden público del 328(1)4 ZPO cuando en el proceso han existido los pretrial discovery. El argumento contrario al reconocimiento se basa en que esta figura inevitablemente da lugar a formas intrusas e injustas de obtener pruebas (lo que en Derecho alemán se conoce como Ausforschungsbeweis), prohibidas por los principios fundamentales del Derecho civil procesal alemán. Los pretrial discovery son instrumentos que pueden utilizar las partes de un proceso, antes del juicio, para descubrir pruebas o para preparar el juicio; por ejemplo interrogatorios, declaraciones o testimonios, peticiones para la admisión de hechos, etc., y están recogidos en las leyes procesales norteamericanas (entre otras, Fed.R.Civ. P. 26-37) ${ }^{17}$. En opinión de Zekoll ${ }^{18}$, en este argumento existe un malentendido sobre el momento de la prueba en los procesos norteamericanos; en otras palabras, que se confunde «prior to trial» o «pretrial», con «pre-pendency». El malentendido de que las pruebas son «pre-pendency» descansa en que en los sistemas de Derecho civil no se distingue entre la fase anterior al proceso y el proceso mismo. Según este autor, resulta difícil para los abogados de países de Derecho civil concebir que el proceso equivalente de recogida de datos en los Estados Unidos puede ser manejado principalmente sólo por las partes. En realidad, la prueba, en el proceso norteamericano, sí requiere que la acción esté pendiente. Además, está disponible la supervisión del tribunal para evitar los posibles abusos. Asimismo, esta figura cumple fines legítimos del proceso; por ejemplo, una de sus funciones es la de salvaguardar contra posibles sorpresas durante el juicio ${ }^{19}$, ya que en los Estados Unidos a las partes del proceso (a diferencia de lo que ocurre en Alemania) normalmente se les prohíbe la recogida de pruebas durante el juicio.

Otro argumento en contra de las diferencias procesales en la prueba entre ambos sistemas descansa en la amplitud de los medios de prueba norteamericanos. Se afirma que los medios de prueba en el Código de procedimiento civil alemán son mucho más limitados. Esta diferencia general, que no deja de ser cierta, no parece que haya sido suficiente para negar el reconocimiento de las sentencias norteamericanas bajo el 328(1)4 ZPO.

17 Vid., Black, H.C., Black's Law Dictionary, 6. edic., St. Paul, Minn., West Publishing Co., 1991, p. 824.

18 Vid. ZeKOLL, «Recognition and Enforcement of American Products...», loc. cit., pp. 331 y ss.

19 Sobre la prueba en el Derecho norteamericano, vid. Note, «Developments in the Law - Discovery», Harvard Law Review, 1961, vol. 74, pp. 940 y ss. 
2. Una de las figuras comúnmente esgrimida para impedir el reconocimiento de las sentencias indemnizatorias norteamericanas ha sido la de los contingent fees, que son los acuerdos realizados entre el abogado y su cliente, y según los cuales el abogado acepta representar al cliente y su honorario será un tanto por ciento de la cantidad que éste reciba en la sentencia; por ejemplo, el $25 \%$ si el caso finaliza con un acuerdo extrajudicial, o el $30 \%$ si el caso llega a juicio. Un acuerdo equivalente con un abogado alemán sería nulo e inválido por aplicación del 138, para 1 del Código civil alemán (BGB).

Los acuerdos contingentes están íntimamente relacionados con la «American rule» ${ }^{20}$ que rige en los Estados Unidos. La aplicación de esta regla tiene como resultado que los honorarios del abogado de la parte ganadora no son un componente de la indemnización, a menos que se autorice por ley o por contrato entre las partes. Sin embargo, debemos tener en cuenta que existen excepciones a esta regla general, por ejemplo, cuando el oponente ha actuado con mala fe, de forma vejatoria, o si el proceso aporta un beneficio substancial a los miembros de un grupo bien definido ( class action»), entre otras. Un principio básico de las reglas procesales europeas es el de que la parte perdedora debe soportar los costes legales en que razonablemente incurra la parte ganadora $^{21}$.

Existe la sospecha de que los jurados norteamericanos tienden a aumentar la cuantía indemnizatoria para compensar por los honorarios de los abogados a la parte ganadora. Se ha dicho que esta carga adicional podría violar el orden público si es incompatible con principios básicos del Derecho alemán, ya que los costes legales de la parte ganadora normalmente consisten en acuerdos contingentes de gran valor económico. El Tribunal Supremo alemán, en 1963, examinó si la figura de los acuerdos contingentes violaba el orden público recogido en el artículo 6

20 BLACK, Black's Law Dictionary, op. cit., p. 53:

"The traditional "American Rule" is that attorney fees are not awardeble to the winning party (i.e. each litigant maust pay his own attorney fees) unless statutorily or contractually authorized; however exceptions exist in that en award may be made to successful party if the opponent has acted in bad faith, vexatiously, wantonly or for oppressive reasons or if the litigation confers a substantial benefit on the members of an ascertaineble class and the court's subject matter jurisdiction makes possible an award that will operate to spread the costs proportionately among them. In addition a court may in its discretion award attorney fees in civil rights actions to the prevailing defendant if the action was frivolous, unreasonable or without foundation. Also, a number of federal statutes make provision for awards of attorney fees to prevailing plaintiffs in actions involving violations of various federal laws (e.g. Fair Labor Standars Act, 16, 29, U.S.C.A. 216(b)).»

${ }^{21}$ Este principio se recoge, por ejemplo, en el artículo $91 \mathrm{ff}$ del ZPO. 
del EGBGB y llegó a la conclusión de que podían ser aceptados, pero debían ser reducidos en su cuantía ${ }^{22}$. En este caso en particular, el valor de la disputa era de aproximadamente 90.000 marcos y el Tribunal redujo el acuerdo contingente del $35 \%$ al $20 \%$. A partir de esta decisión se generalizó la idea de que «todos» los acuerdos contingentes de honorarios de abogados debían ser examinados y reducidos ${ }^{23}$. Esta decisión ha sido nuevamente interpretada por la sentencia que más adelante comentaremos.

3. El quantum de las partidas indemnizatorias concedidas en las sentencias norteamericanas también ha sido motivo de disputa en el reconocimiento y ejecución de dichas sentencias en Alemania. No existen diferencias esenciales entre los Estados Unidos y Alemania sobre los ítemes que generalmente se indemnizan como daños compensatorios. Bajo ambos órdenes legales la víctima tiene derecho a recibir indemnización por todos los daños que sufra como consecuencia del acto ilícito (daños a la propiedad, pérdida de salarios, gastos médicos y daños morales). Los daños económicos no son objeto de controversia porque es posible realizar sobre ellos una determinación económica más o menos objetiva y por lo tanto no violan la cláusula de orden público del 328(1)4 ZPO. Sin embargo, sí ha existido cierta discusión sobre los daños morales (pain and suffering) ya que normalmente el quantum indemnizatorio que se concede en los Estados Unidos por este concepto es superior a lo que indemnizan los Tribunales alemanes por lesiones similares. Por un lado, existe la sospecha de que los jurados norteamericanos tácitamente incrementan esta partida para compensar en ella no sólo los daños morales sufridos por la víctima sino también los costes legales en los que ésta ha incurrido ${ }^{24}$. La doctrina mayoritaria alemana ha llegado a la conclusión de que, aunque esta sospecha fuese cierta, no se estaría dañando el orden público del foro, porque el artículo $91 \mathrm{ZPO}$ ordena que la parte perdedora soporte todos los costes, incluyendo los costes legales, en que razonablemente incurra la parte ganadora. Además, la

22 BGHZ, 44, 183, 190 (1965). Este caso no trataba sobre reconocimiento de una sentencia extranjera, sino sobre la ley aplicable de acuerdo al Derecho internacional privado alemán.

23 Vid. STIEFEl, STÜRNER, STADLER, «The Enforceability of Excessive...», loc. cit, p. 797. En opinión de estos autores, esta decisión provee de guía para el test de orden público de las indemnizaciones extranjeras en las que se encuentran escondidos los costes legales. En su opinión, no violarían la cláusula del orden público acuerdos contingentes de honorarios de abogados que fuesen del 30 al $10 \%$.

24 Vid. ZeKoll, «Recognition and Enforcement of American Products...», loc. cit., pp. 320-321. 
prohibición de revisar el fondo del asunto impide un análisis por parte del tribunal alemán de los motivos que llevaron al jurado a conceder la indemnización por daños morales.

Por otro lado, las indemnizaciones de Tribunales norteamericanos de daños morales también han sido motivo de ataque, por parte de los demandados que buscan el no reconocimiento de la sentencia en Alemania, basándose en que son contrarias al principio de proporcionalidad de la Constitución alemana y consecuentemente violan el orden público $^{25}$. En primer lugar, de acuerdo con el 253 del BGB los daños morales no son la regla general sino una excepción al principio legal básico de compensación. El 847.1 del BGB restringe las indemnizaciones de daños morales a las lesiones del cuerpo o en la salud y privación de libertad ${ }^{26}$. ¿Qué ocurre cuando una indemnización por daños morales norteamericana concede una cuantía muy superior a la que hubiese sido concedida por un tribunal alemán ante una situación y unos daños similares?, ¿cuál es el criterio que se debe aplicar?

Han sugerido algunos autores ${ }^{27}$ que una oscilación del $50 \%$ debería ser permitida, y por lo tanto una indemnización que ascendiese al doble de lo que se hubiera indemnizado en Alemania bajo el Derecho alemán no dañaría el orden público. El Oberlandesgericht (OLG) de Düsseldorf consideró tolerable una cantidad que excedió 4 veces a la que hubiera sido concedida por un tribunal alemán. En opinión del OLG, cualquier cantidad que excediese a la anterior «trascendería todos los límites razonables» ${ }^{28}$ con lo que no podría ser reconocida bajo el 328(1)4 ZPO.

Las indemnizaciones de pain and suffering son valoradas de acuerdo con la gravedad de la lesión, magnitud, duración del dolor, las circunstancias de los agentes ilícitos, su culpabilidad, y la situación económica del demandado y el demandante. En opinión de un sector de la doctrina alemana ${ }^{29}$, estos criterios tienen en cuenta el principio de compensación razonable de la misma forma que los Tribunales alemanes hacen cuando calculan la cantidad indemnizatoria en un caso individual,

25 Una indemnización de daños desproporcionada puede infringir las libertades individuales del demandado, con lo que se produciría una violación de la Constitución. Para más detalles ver Tribunal Constitucional Federal alemán (B.Verf.GE), vol. 34, pp. 269-285.

${ }^{26}$ Parece dudoso el carácter de principio esencial de esta regla ya que el Tribunal Supremo alemán permite excepciones a ella.

27 Vid. HAY, «The Recognition and Enforcement of American...», loc. cit., p. 740.

28 Recht der internationalen Wirtschaft (RIW), vol. 37 (1991), p. 594.

${ }^{29}$ La doctrina alemana a favor de esta postura la recogen STIEFEL, STÜRNER y STADLER, «The Enforceability of Excessive...», loc. cit., p. 792. 
con lo que las indemnizaciones por pain and suffering pueden ser reconocidas y ejecutadas en Alemania siempre y cuando la indemnización concedida en ellas no sea desproporcionada ${ }^{30}$.

4. La aplicación del artículo 38 del EGBGB como límite al reconocimiento de sentencias extranjeras en Alemania ha sido una cuestión muy debatida en el pasado. El artículo 38 EGBGB, en principio, regula los conflictos de leyes y de acuerdo con el artículo 32 EGBGB se presupone la aplicación del Derecho de daños del país en el que aconteció el acto ilícito. Sin embargo, el artículo 38 EGBGB proporciona un paraguas protector para los agentes ilícitos con nacionalidad alemana: la responsabilidad por un ilícito cometido en el extranjero por un nacional alemán no puede exceder de lo que le habría correspondido si el acto ilícito se hubiera producido en Alemania ${ }^{31}$. ¿Es aplicable este artículo al reconocimiento y ejecución de sentencias extranjeras de indemnización de daños? $?^{32}$.

Un sector de la doctrina ha apoyado la aplicación del artículo 38 EGBGB en la esfera del reconocimiento de sentencias, lo que significaría que las indemnizaciones superiores a las concedidas en Alemania para supuestos similares no podrían ser reconocidas ${ }^{33}$. Estos autores establecen un nexo lógico entre el artículo 38 EGBGB y la cláusula de orden público internacional recogida en el artículo 6 EGBGB. De acuerdo con esta interpretación en primer lugar, ambos artículos están basados en un mismo concepto; el artículo 6 opera como lex generalis contra la aplicación de leyes extranjeras inaceptables, mientras que el

30 Esta opinión doctrinal ha sido refrendada por la jurisprudencia del Tribunal Supremo alemán en la sentencia de 1992 que más abajo examinaremos.

${ }^{31} \mathrm{El}$ artículo 5 EGBGB establece que la nacionalidad alemana es la relevante cuando una persona tiene doble o múltiple nacionalidad.

32 Esta cuestión se planteó en el contexto de la Convención de Bruselas relativa a la competencia judicial y a la ejecución de resoluciones judiciales en materia civil y mercantil (1968). La Convención obliga, dentro de la Comunidad Europea, al reconocimiento de todas las sentencias jurisdiccionalmente válidas, pero establece en el artículo 27.1 que una sentencia no será reconocida si viola el orden público del Estado receptor. En una decisión del Tribunal Supremo de 1983 (BGHZ 88, 17 (1983)) se declinó incluir dentro de la definición de orden público la regla del artículo 38 EGBGB. El Alto Tribunal confinó el artículo 38 a la cuestión de la elección de la ley aplicable (conflicto de leyes). Sin embargo, esta decisión no aclaró si el mismo principio debería ser aplicable cuando el reconocimiento y ejecución de sentencia se solicitase fuera del marco de la Convención de Bruselas, es decir, según el 722 y 723 ZPO.

33 MARTINY, «Recognition and Enforcement...», loc. cit., p. 744; HAY, «The Recognition and Enforcement of American...», loc. cit., pp. 737-738; REQUEJO ISIDRO, «Reconocimiento en España...», loc. cit., p. 90. 
artículo 38 EGBGB, como subcategoría específica, meramente implementa las nociones alemanas de orden público para mitigar los efectos de las leyes de daños extranjeras ${ }^{34}$. En segundo lugar, para solventar las diferencias existentes entre aplicación y reconocimiento, estos autores suponen que la utilización de un mismo lenguaje en el artículo 6 EGBGB y el 328(1)4 ZPO significa que se debe aplicar un estándar común de orden público para las leyes extranjeras y para las sentencias extranjeras $^{35}$.

Sin embargo, ésta no deja de ser la opinión minoritaria, ya que la gran mayoría de la doctrina alemana considera que el ámbito de aplicación del artículo 38 EGBGB debe estar limitado al conflicto de leyes y que el orden público aplicable al reconocimiento de sentencias es únicamente el recogido en el 328(1)4 $\mathrm{ZPO}^{36}$.

\section{Decisiones alemanas}

La primera decisión de un tribunal alemán sobre una condena de daños punitivos norteamericana es la del Oberlandesgericht de Munich, de 9 de mayo de $1989^{37}$, que se pronunció a favor de la aplicación de los Convenios de La Haya en materia de asistencia judicial internacional al

34 Las opiniones doctrinales sobre la aplicación del artículo 38 EGBGB, las recoge ZEKOLL, «Recognition and Enforcement of American Products...», loc. cit., p. 314.

35 ZEKOLL, «Recognition and Enforcement of American Products...», loc. cit , estima que estas dos premisas dan lugar a un resultado incierto. Primero, es dudoso que el artículo 38 y el 6 EGBGB compartan las mismas bases conceptuales. El orden público contenido en el artículo 6 EGBGB permite la aplicación de la ley extranjera por los Tribunales alemanes en todos los casos, menos para circunstancias excepcionales. Así, sólo si la aplicación de la lex causae en el caso individual entra en conflicto con principios jurídicos alemanes de importancia fundamental sustituirá el Derecho alemán al Derecho extranjero. El acento se coloca en el «caso particular», no en el Derecho extranjero per se. Por el contrario, la aplicación del artículo 38 EGBGB se hace de una forma mecánica que da lugar a una negativa en la aplicación de las leyes extranjeras de daños. ZEKOLL considera que las consecuencias drásticamente diferentes del artículo 6 y del artículo 38 EGBGB plantean dudas considerables sobre la tesis de que comparten bases conceptuales comunes. Además, aunque el artículo 38 EGBGB sea considerado como una subcategoría del artículo 6 EGBGB, sería dudoso el que la «violación» de estos artículos por una sentencia extranjera justificase su no reconocimiento, puesto que el concepto de orden público en el Derecho internacional privado (art. 6 EGBGB) no es equivalente al concepto de orden público que se maneja en el reconocimiento de sentencias (art. 328(1)4 ZPO). Pp. 314-316.

${ }^{36}$ La opinión mayoritaria considera que los esfuerzos por aplicar el artículo 38 EGBGB al reconocimiento de sentencias reflejan una postura anticuada que trata de proteger los intereses nacionales a expensas de los esfuerzos hacia una mayor integración internacional.

37 Recht der internationalen Wirtschaft (RIW), vol. 35 (1989), p. 483. 
régimen de comunicaciones en procesos de daños punitivos. El Tribunal alemán se pronunció a favor del carácter civil de la institución basándose en que la condena de daños punitivos no da lugar a antecedentes penales para el demandado, que existe independientemente de que recaiga sanción penal sobre el mismo asunto y en que las condiciones para su otorgamiento son las del Derecho garantías propias del Derecho penal ${ }^{38}$.

La segunda sentencia es la del Oberlandesgericht de Berlín, de 13 de junio de $1989^{39}$, en la que se trataba un caso de productos defectuosos en que el daño lo había causado una máquina fabricada en Alemania. El Tribunal de Berlín negó el reconocimiento de la sentencia indemnizatoria norteamericana.

Con posterioridad, la sentencia del Oberlandesgericht de Düsseldorf, de 28 de mayo de $1991^{40}$, declaró que los daños punitivos sólo tenían una función compensatoria pero redujo su quantum a la cantidad que consideró en consonancia con dicha función. Finalmente, encontramos la sentencia del Bundesgerichtshof, de 4 de junio de $1992^{41}$, que casa la sentencia anterior del Tribunal de Düsseldorf. La sentencia del Alto Tribunal niega el reconocimiento de la partida punitiva y otorga el reconocimiento para el resto de partidas indemnizatorias ${ }^{42}$.

En materia de notificación de una sentencia procedente de los Estados Unidos existen también las sentencias del OLG de Munich, de 15 de julio de $1992^{43}$ y la sentencia del OLG de Düsseldorf, de 19 de

38 Vid., Requejo Isidro, M., «Punitive Damages y su notificación en el contexto del Convenio de La Haya de 15 de octubre de 1965», Revista Española de Derecho Internacional, 1996, p. 76. «Niega la consideración de los punitive damages como institución penal, apoyándose en criterios de carácter formal...»

39 Recht der internationalen Wirtschaft (RIW), vol. 35 (1989), p. 988.

40 Recht der internationalen Wirtschaft (RIW), vol. 37 (1991), p. 594.

${ }^{41}$ BGH, de 4 de junio de 1992, Zeitschrift für Wirtschaftsrecht und Insolvenzpraxis (ZPI), 17/92, p. 1.256. Esta sentencia será objeto de nuestro análisis en páginas posteriores.

${ }^{42}$ Los Tribunales suizos también se han visto obligados a contestar cuestiones relacionadas con los daños punitivos: La sentencia de 1 de octubre de 1982 del Tribunal de Sargas negó la ejecución en base a la naturaleza penal de los daños punitivos; Sentencia de 1 de febrero de 1989 del Tribunal de Basilea (Security Forwarders Inc. v. Trans Container Services AG), Basler Juristische Mitteilungen 1991, p. 31; Court of Appeals Basel Stadt, 1 de diciembre de 1989, Basler Juristische Mitteilungen 1991, p. 38; appeals dismissed de 12 de julio de 1990, Swiss Federal Supreme Court BGH 116 II 376; and Siehr RIW 1991, p. 705. En esta sentencia no se consideró que los daños punitivos tuvieran naturaleza penal. Estas sentencias se recogen en STIEFEl, STÜRnER, STADLER, «The Enforceability of Excessive...», loc. cit., p. 781 y en R. ISIDRO, «Reconocimiento en España...», loc. cit , p. 92.

43 Sentencia del OLG de Munich, de 15 de julio de 1992, Recht der internationalen Wirtschaft (RIW), 1993, pp. 70-71. 
febrero de $1992^{44}$. Ambas defienden la naturaleza civil de los daños punitivos.

\section{Daños punitivos}

\section{Definición, antecedentes y funciones de los daños punitivos}

La doctrina de los daños punitivos recibió su primera articulación explícita en Inglaterra, en el caso Wilkes v. Wood ${ }^{45}$, en 1763. En Gran Bretaña, la figura fue modificada en 1964 por Lord Devlin en Rookes v. Barnard ${ }^{46}$. En este caso, Lord Devlin consideró que la partida indemnizatoria conocida como daños punitivos o daños ejemplares era una anomalía. En su opinión, la figura de los «daños agravados» explicaba muchos de los casos que hasta ese momento habían sido considerados como supuestos de daños punitivos ${ }^{47}$. La reforma iniciada por Lord Devlin ha tenido como consecuencia que la importancia económica de esta partida en Inglaterra sea, en la actualidad, reducida. Sin embargo, en los Estados Unidos los daños punitivos tienen una mayor relevancia que en el resto de los países de la common law ${ }^{48}$.

44 Sentencia del OLG de Düsseldorf, de 19 de febrero de 1992, NJW, 1992, pp. 3.1103.112 .

452 Wils K.B. 203, 95 Eng.Rep. 766, C.C.P. 1763. También aparece en Huckle v. Money; 2 Wils KB 205, 95 Eng.Rep. 768 (1763).

46 Rookes v. Barnard 1 All E.R. 367 (A.C. 1964).

47 En Rookes se limitaron los daños ejemplares a tres categorías:

1. Las acciones inconstitucionales, arbitrarias u opresivas de los empleados del Gobierno.

2. Cuando la conducta del demandado ha sido calculada para obtener un beneficio que excede la compensación en la que posiblemente incurriría si es declarado responsable.

3. Cuando una ley expresamente los autorice.

48 En Australia, por ejemplo, aunque la aplicación de los principios establecidos por Lord Devlin en el caso Barnard ha sido rechazada expresamente, los daños punitivos no han alcanzado la importancia económica que tienen en los Estados Unidos. En Canadá, el Tribunal Supremo aceptó la división trazada en el caso Barnard entre daños agravados y daños punitivos y también aceptó sus recomendaciones, pero se negó a aceptar que los daños punitivos fuesen reducidos a las tres categorías establecidas en el caso inglés (una excepción la encontramos en la provincia de Columbia, en la que se sigue la postura inglesa). Sin embargo, tampoco en Canadá son conocidas las condenas millonarias por daños punitivos (a excepción de Claiborne Industries Ltd. v. National Bank of Canada (69 O.R. (2d) 65) de 1989 en el que se concedió una indemnización punitiva de 4.800 .00 dólares). Un estudio realizado en Canadá, Report on Exemplary Damages, por la Ontario Law Reform Commission, en 1991 llegó a la conclusión de que los daños punitivos no son en Canadá la causa, o una de las causas, de la «crisis de las aseguradoras». 
Los daños punitivos se conceden a la parte demandante, históricamente, para castigar y desincentivar conductas ilícitas intencionales, maliciosas, temerarias, y comportamientos ultrajantes ${ }^{49}$. La mayoría de los Tribunales norteamericanos, incluyendo los de Nueva York, sostienen que los daños punitivos no constituyen compensación por la lesión o por el daño sufrido por la víctima, sino que son penas privadas impuestas por los jurados civiles para castigar conductas censurables y para disuadir de conductas futuras semejantes.

En los orígenes de los daños punitivos se ve clara la intención de utilizarlos como forma de compensar a la persona lesionada por aquellas pérdidas que el Derecho no reconocía; por ejemplo, los daños morales. Hoy, esta función no se sostiene puesto que la amplia categoría de pain and suffering ${ }^{50}$ comprende muchos (si no todos) de aquellos daños que en el pasado no eran indemnizables y ahora sí lo son. La función compensatoria ha dejado de ser alegada en los Tribunales y no

49 El Restatement (Second) of Torts los define en la sección 908:

1) Los daños punitivos son daños, distintos de los daños compensatorios o de los daños nominales, que se indemnizan en contra de una persona para castigarla por su conducta ultrajante y para disuadirla a ella y a otras de conductas similares en el futuro.

2) Los daños punitivos pueden ser indemnizados por una conducta que es ultrajante, debido a su motivación perversa o a su descuidada indiferencia hacia los derechos de los otros. En la valoración de los daños punitivos, el trier of fact puede adecuadamente considerar el carácter del acto del demandado, la naturaleza y la extensión del daño de la víctima que el demandado ha causado o ha intentado causar, y la riqueza del demandado.

American Law Institute, Restatement of the Law, (Second) of Torts, St. Paul, Minn., 1966-1982.

En el Blacks Law Dictionary, op. cit., p. 352, se recoge una definición de esta figura resultado de la síntesis de casos de todas las jurisdicciones que puede ser útil:

«Exemplary or punitive damages. Exemplary damages are damages on an increased scale, awarded to the plaintiff over and above what will barely compensate him for his property loss, where the wrong done to him was aggravated by circumstances of violence, oppression, malice, fraud, or wanton and wicked conduct on the part of the defendant, and are intended tosolace the plaintiff for mental anguish, laceration of his feelings, shame, degradation, or other aggravations of the original wrong, or else to punish the defendant for his evil behavior or to make an example of him, for which reason they are also called "punitive": or "punitory" damages or "vindictive" damages. Unlike compensatory or actual damages, punitive or exemplary damages are based on an entirely different public policy consideration that of punishing the defendant or of setting an example for similar wrongdoers, as above noted. In cases in which it is proved that a defendant has acted willfully, maliciously, or fraudulently, a plaintiff may be awarded exemplary damages in addition to compensatory or actual damages. Damages other than compensatory damages which may be awarded against person to punish him for outrageous conduct. Wetherbee vs. United Ins. Co. of America, 18 C.A.3d, 95 Cal. Rptr. 678, 680.»

${ }^{50} \mathrm{El}$ «pain and suffering» anglosajón comprende el dolor y sufrimiento de la víctima como consecuencia del daño. 
aparece en la mayoría de los Códigos estatales ${ }^{51}$. La función de castigo del agente ilícito, al igual que la anterior, ha acompañado a los daños punitivos desde su origen. Si bien, y a diferencia de la función compensatoria, se ha mantenido en el tiempo ${ }^{52}$, a pesar de ser la causa del mayor número de críticas. Las críticas se basan principalmente en la distinción clásica entre el Derecho civil y el penal, a los daños punitivos se les critica duramente porque suponen la introducción de un fin punitivo en un Derecho de tort cuyo único fin, en principio, debe ser el compensatorio. Por último, se alega la función disuasoria que los daños punitivos ejercen sobre el agente ilícito y sobre la sociedad.

El apoyo a esta función - y por lo tanto a los daños punitivos- ha venido en los últimos tiempos de manos del «Análisis Económico del Derecho» ${ }^{53}$. Un grupo importante de autores de la escuela de Chicago mantiene la teoría de que los responsables de la lesión deben soportar los costes totales de su actividad, y que éstos no son siempre iguales a los daños compensatorios, por lo que en ciertos supuestos es recomendable una condena de cuantía superior a los daños reales sufridos por el demandante. A favor de la función disuasoria se dice que, si es efectiva, llevará a unos niveles óptimos de seguridad. Niveles que se lograrían condenando a una gran suma de dinero, de tal forma que para el demandado en ningún momento resulte rentable la comisión del acto ilícito. Se dan supuestos,

51 La excepción la encontramos en Connecticut, Georgia, Michigan y New Hampshire, en donde aunque se usan los términos daños ejemplares o punitivos, su naturaleza es claramente compensatoria.

52 Delaware es la única jurisdicción en la que el castigo es el único propósito en la imposición de los daños punitivos. El Tribunal de Delaware estableció en Riegel v. Aastad, 272 A2d 715, 718 (Del 1970) que «Los daños punitivos o ejemplares no se indemnizan como forma de recompensar por la lesión, sino como forma de castigo al agente ilícito cuando el acto ilícito fue cometido "wilfully or wantonly" ».

${ }^{53}$ Los daños punitivos han sido tratados desde el punto de vista de «análisis económico del Derecho» en múltiples artículos:

ABRAHAM, K. y JEFFRIES, J., «Punitive damages an the rule of law: the role of the defendant's wealth», en Journal of Legal Studies, vol. 18, 1989, pp. 415-425; CHAPMAN, B. y TREBILCOCK, M.J., «Punitive damages: detterence in search of a rationale», en Alabama Law Review, vol. 40, 1989, pp. 741-829; ElLIS, D.D., «Fairness and Efficiency in the Law of Punitive Damages», en South California Law Review, vol. 56, 1982, pp.1 y ss.; Johnston, «Punitive liability: A new paradigm of efficiency in tort law», en Columbia Law Review, vol. 87, 1987, pp. 1.385 y ss.; MANN, K., «Punitive civil sanctions: the middleground between criminal and civil law», en Yale Law Journal, vol. 101, 1992, pp. 1.795-1.873; OwEN, D.G., «Problems in assessing punitive damages against manufactures of defective products», en University of Chicago Law Review, vol. 49, 1982, pp. 1-60; «Punitive damages in Product Liability Litigation», en Michigan Law Review, vol. 74, 1976, pp. 1.257 y ss.; «Civil punishment and the public good», en S. Cal. Law Review, vol. 56, 1982, pp. 103 y ss.; «Deterrence and Desert in Tort: A Comment», en California Law Review, vol. 73, 1985, pp. 665-676. 
principalmente en el mundo de la empresa, en los que para la persona física o jurídica es más rentable económicamente la realización del acto ilícito y el posterior - y posible- pago de la condena a daños compensatorios, que la no realización de la actividad. No existen datos empíricos sobre el efecto de esta función en la población. Ha recibido abundantes críticas por parte de la doctrina, no tanto por sí misma, sino por su falta de efectividad y su puesta en práctica por medio de los jurados. Se alega que el efecto preventivo no se cumple porque los procesos civiles son por lo general lentos, las cantidades concedidas impredecibles, y los jurados no están preparados para realizar esta función de forma eficiente.

Tradicionalmente, la cuantía indemnizada por daños punitivos en las acciones civiles se calculaba según la gravedad del acto del demandado. Sin embargo, los demandantes argumentaron que para que los daños punitivos actuasen como castigo adecuado por la conducta ultrajante y como función disuasoria efectiva de futuras conductas, la cuantía económica de esta partida debía guardar cierta relación con la riqueza del demandado. En la actualidad, usualmente es la riqueza o el capital del demandado, junto con la naturaleza de su comportamiento, la que dicta el nivel de la indemnización punitiva concedida al demandante.

El Derecho de daños de los Estados Unidos está en proceso de redefinición, y por lo tanto sujeto a cambios y revisiones ${ }^{54}$. Un caso reciente del Tribunal Supremo de los Estados Unidos - BMW of North America, Inc. V. Gore- puede dar lugar a un enfriamiento en las grandes indemnizaciones punitivas concedidas por los jurados en los tribunales federales. En BMW of North America, Inc. v. Gore ${ }^{55}$, el Tribunal Supremo revocó la sentencia del Tribunal Supremo de Alabama —en la que se indemnizaba con 2 millones de dólares por daños punitivos- basándose en que esta in-

${ }^{54}$ En diciembre de 1994 la National Conference of Commissioners on Uniform State Laws propuso un modelo de Ley de daños punitivos uniforme para todos los Estados de la Unión que todavía no ha sido aprobado.

55116 S.Ct. 1589 (1996). Los hechos fueron que Ira Gore, Jr. demandó a BMW bajo el Derecho de Alabama reclamando daños compensatorios y punitivos por el daño sufrido en 1990 cuando adquirió un automóvil BMW nuevo en un concesionario autorizado. Transcurridos unos meses desde la fecha de la compra, Gore descubrió que el automóvil había sido repintado y entabló la demanda. Gore alegaba que había sufrido daños como consecuencia de que BMW no había informado sobre el hecho de que el automóvil había sido repintado antes de su venta. En el juicio, BMW admitió que no informaba a los concesionarios cuando un coche nuevo había sufrido un daño antes de la entrega, si el coste de la reparación no excedía del 3\% del precio de venta del automóvil. El jurado encontró a BMW responsable por daños compensatorios en la cantidad de 4.000 dólares y 4 millones de dólares por daños punitivos. BMW pidió al juez la anulación de la indemnización punitiva, pero este concluyó que la indemnización no era "grossly excessive». El Tribunal Supremo de Alabama redujo la indemnización punitiva a 2 millones de dólares. 
demnización constituía una violación de la enmienda catorce de la Constitución norteamericana, la «Due Process Clause» ${ }^{56}$. El Tribunal Supremo concluyó que la indemnización punitiva multimillonaria era excesiva en comparación con la indemnización compensatoria de 4.000 dólares. En esta decisión el Tribunal Supremo enunció tres indicadores para los tribunales cuando deban considerar una indemnización de daños punitivos:

1) el grado de reprensión de la conducta del demandado (a la que los tribunales deben dar más peso);

2) la proporción entre los daños punitivos y el daño real sufrido;

3) la diferencia entre la indemnización de daños punitivos y las sanciones civiles o criminales que los tribunales pudieran imponer por actos ilícitos similares.

Las orientaciones anteriores parecen indicar un intento por parte del Tribunal Supremo de restringir las indemnizaciones punitivas que no guarden una relación razonable con el daño sufrido por la víctima. Hasta el momento, los Tribunales federales han sido receptivos a la iniciativa del Tribunal Supremo. Pero los Tribunales estatales parecen menos dispuestos a aceptar la decisión anterior. Claramente, el caso BMW no es la panacea para los males de las empresas demandadas, por lo que se espera que las grandes corporaciones continúen con sus actividades para lograr una reforma de la ley estatal y federal que afecta a las indemnizaciones de daños punitivos.

\section{Naturaleza de la indemnización de daños punitivos}

La cuestión previa a la que se debe enfrentar el tribunal alemán, competente para otorgar el reconocimiento o no de una indemnización que contiene daños punitivos, es la del examen de la naturaleza civil o

56 «Due Process». «All persons born and naturalized in the United States, and subject to the jurisdiction thereof, are citizens of the United States and of the State wherein they reside. No State shall make or enforce any law which shall abridge the privilegies or inmunities of citizens of the United States, nor shall any State deprive any person of life, liberty or property, without due process of law; nor deny any person within its jurisdiction the equal protection of the laws», U.S. Constitution, 14 th Amendment.

La cláusula de «due process» no está constreñida al ámbito de lo penal; se aplica a cualquier procedimiento legal o régimen por el que una persona puede ser privada de «life, liberty or property». Obliga a que los procedimientos legales sean consistentes con la «justicia material», que estén en consonancia con las «nociones ordinarias de juego justo y las reglas establecidas por el derecho», que esté de acuerdo con las «nociones tradicionales de juego justo y justicia sustancial». El primer caso que reconoció que se podía estar violando el requisito constitucional de «due process» fue Juzwin v. Amtrong Trading Corp (1989 WL 19962 (D NJ 1989). 
criminal de la figura. El artículo $328 \mathrm{ZPO}$ exige como prerrequisito al reconocimiento de la sentencia, aunque no lo menciona expresamente, que la cuestión sea civil o mercantil. A pesar de que este criterio ha sido aplicado de forma liberal por los Tribunales alemanes, la clasificación de los daños punitivos como cuestión civil o mercantil ha dado lugar a cierta controversia. Evidentemente, las dudas sobre la figura provienen de las funciones de disuasión y castigo, comentadas más arriba, que no parecen encontrar un fácil alojamiento en las divisiones de ilícito civil y penal del derecho continental. Se ha argumentado que estas indemnizaciones no pueden ser reconocidas y ejecutadas en Alemania por su naturaleza penal ${ }^{57}$, pero este argumento ha sido discutido por la doctrina mayoritaria ${ }^{58}$ que relega la función punitiva a un posterior análisis de su conformidad con el orden público y fija su atención principalmente en criterios formales.

Se invoca en primer lugar que las partes de la disputa, el demandado y el demandante, son particulares; en segundo lugar, que la indemnización se concede a un particular y no al Estado ${ }^{59}$; y en tercer lugar, que las normas que gobiernan la disputa son las propias del procedimiento civil ${ }^{60}$. Algunos autores ${ }^{61}$ han recurrido al hecho, dudoso, de que también en el Código civil alemán se contienen estipulaciones que permiten cláusulas penales en los contratos privados y su ejecución en el caso de incumplimiento del contrato ${ }^{62}$.

Los argumentos favorables a la naturaleza civil de los daños punitivos, en especial el argumento de que la indemnización se abona a un

57 Vid., Martiny, «Recognition and Enforcement...», loc. cit., p. 748; STIEFEL, STÜRNER, STADLER, «The Enforceability of Excessive...», loc. cit , p. 784.

58 A favor, vid. ZEKOLL, «Recognition and Enforcement of American Products...», loc. cit., p. 316; STIEFEL, STÜRNER, STADLER, «The Enforceability of Excessive...», loc. cit., pp. 785-786.

59 Este argumento está basado, entre otras, en la sentencia del Tribunal Supremo de los Estados Unidos, Browning-Ferries Industries v. Kelco Disposal, Inc. (109 S.Ct. 2909 (1988)) en donde se sostuvo que el argumento decisivo en el análisis de la naturaleza de los daños punitivos es que estos son abonados al particular y no al Estado. En apoyo de la naturaleza civil de los daños punitivos se pronunció también la Comisión especial de La Haya, de 17 a 20 de abril de 1989. El Informe recoge la opinión mayoritaria que se decanta a favor del carácter civil o comercial, apoyada por el hecho de que la partida punitiva se abona al particular y no al Estado. Sobre el Informe vid. ReQueJo Isidro, Punitive Damages y su notificación..., pp. 76-77.

60 Vid., ZeKoll, «Recognition and Enforcement of Ameritan Products...», loc. cit., p. 324.

${ }^{61}$ Para un análisis de las cláusulas penales en el Derecho alemán, vid. STIEFEL, STÜRNER, STADLER, «The Enforceability of Excessive...», loc. cit., pp. 785 y ss.

62 Artículo 339 y ss. Bügerliches Gesetzbuch (BGB). Esta cuestión parece estar más relacionada con el análisis de la conformidad de los daños punitivos con el orden público que con el análisis de su naturaleza civil o penal. 
particular, no es aplicable a todos los Estados de la Unión. Las reformas emprendidas por algunos Estados en los últimos años han llevado a que se aprueben leyes en las que cierta cantidad de los daños punitivos debe ser abonada al Estado o a alguna institución dependiente de él ${ }^{63}$. Sin embargo, hay quien ve en estas reformas un apoyo a la naturaleza privada de la parte de daños punitivos que corresponde a la víctima ${ }^{64}$.

La postura favorable a la naturaleza civil de los daños punitivos es la que se ha sostenido en los Tribunales alemanes a partir de la sentencia del OLG de Munich, de 9 de mayo de 1989, en Alemania ${ }^{65}$, y la sentencia de 1 de febrero de 1989 del Tribunal de Basilea, en Suiza ${ }^{66}$.

\section{Daños punitivos versus Orden público alemán}

El artículo 328(1)4, en el que se recoge la cláusula del orden público, ha sido el más alegado contra el reconocimiento de los daños punitivos. Además, éste es el único que, aún hoy, es aplicado por los Tribunales para negar el reconocimiento y la ejecución de sentencias norteamericanas de daños punitivos.

Partiendo de la declaración de la naturaleza civil de los daños punitivos la doctrina y la jurisprudencia alemana han analizado sus funciones y

63 Vid., Colorado (Colo. Rev. Stat. 13-21-102(4) (1988), en Florida (Fla. Stat. Ann. 768.72(2) (1988) el 60\% debe ser abonado al Public Medical Assistance Trust Fund o al General Revenue Fund; en Georgia (Ga. Code Ann. 51-12-5.1(e)(2) (1987)) en el que el 75\% debe ser abonado al Dept. Of Administrative services; en Illinois (III. Rev. Stat. Cap. 110, 2-1207 (1986)) el tribunal tiene poder discrecional para distribuir la indemnización correspondiente a daños punitivos; en Iowa (Iowa Code Ann. 668.1(2)(b) (1987) el 75\% debe ser abonado al Civil Reparation Trust; en Missouri (Mo. Ann. Stat. 537.675 (1987)) el $50 \%$ debe ser abonado al Tort Victims Compensation Fund; en Oregon (Or. Rev. Stat. 18.540 (1988)) el 50\% debe ser abonado al Criminal Injuries Compensation Account, y en Utah (Utah Code Ann. 78-18-1(3) (1989)) el 50\% de la cantidad que exceda de 20.000 dólares debe ser abonado a un fondo estatal.

64 Son de esta opinión, Stiefel, Stürner, Stadler, «The Enforceability of Excessive...», loc. cit., pp. 785-786.

${ }^{65}$ Recht der internationalen Wirtschaft, (RIW), vol. 35 (1989), p. 483. Sobre la sentencia del OLG de Munich de 9 de mayo de 1989, ver REQueJo IsIDRo, «Punitive Damages y su notificación...», loc. cit., pp. 76-77. Esta autora también reconoce que existen opiniones contrarias que afirman la preponderancia de la función penal «pero la autoridad que lógicamente confiere a la afirmación de la naturaleza civil de los punitive damages el hecho de encontrar apoyo en la Comisión de 1989 ha contribuido a rebajar notablemente el número de opiniones disidentes». Pp. 77-78.

66 Sentencia de 1 de febrero de 1989 del Tribunal de Basilea (Security Forwarders Inc. v. Trans Container Services AG. Recogida en REQueJo IsIDRo, «Reconocimiento en España...», loc. cit., p. 92. 
las han contrastado con la cláusula de orden público. Los autores que abogan por su conformidad el artículo 328(1)4 ZPO se apoyan principalmente en la función compensatoria de la partida y en la existencia de instituciones en el Derecho civil alemán que también ejercen la función de castigo o punitiva. La jurisprudencia y gran parte de la doctrina no han aceptado estos argumentos, y salvo alguna excepción, han puesto su acento en la función de castigo de los daños punitivos contraria al orden público alemán, en la negativa a aceptar instituciones del Derecho privado con funciones de castigo, y en el principio de proporcionalidad de la Constitución alemana. A continuación, analizaremos los argumentos a favor y en contra del reconocimiento y ejecución de los daños punitivos norteamericanos.

\section{a) Argumentos a favor}

Los argumentos a favor de la conformidad de los daños punitivos con el orden público del foro van encaminados, principalmente, a potenciar la función compensatoria de la partida frente a las otras funciones (de castigo y disuasoria) ${ }^{67}$. Se niega que la función principal de estos daños sea la de castigo o la disuasoria, y se afirma la función de compensar por otros daños que no son compensados por el Derecho norteamericano, pero que son reales para la víctima. En un primer momento, se dijo que los daños punitivos servían para compensar por los daños morales sufridos por el demandante, pero hoy esta afirmación no se mantiene, porque como vimos más arriba la partida de pain and suffering ha sido interpretada de forma amplia, tanto por la doctrina como por la jurisprudencia de los Estados Unidos, para incluir en ella todos los daños morales que pueda sufrir la víctima de un agente ilícito ${ }^{69}$. En segundo lugar, se ha dicho que sirven para compensar por los costes legales de la parte ganadora, costes que, como también vimos, en el Derecho norteamericano no se consideran parte de la indemnización. Este fue el razonamiento de la sentencia del OLG de Düsseldorf, de 28 de mayo de 1991. El Tribunal consideró que la partida de daños punitivos buscaba la satisfacción de los costes legales del demandante y los redujo a la cantidad que por ese concepto se habría indemnizado en Alemania (del $40 \%$ al 25\% de

67 Vid. vON WeStPHALEN, «Punitive Damages in US-amerikanischen Produkthaftungsklagen und der Vorbehalt des Art. 12 EGBGB», 1981, R. Intl. Wirt. 141 y ss., citado en ZEKOLL, «Recognition and Enforcement of American Products...», loc. cit., p. 326.

68 Un artículo clásico en la doctrina norteamericana es OwEN, «Punitive Damages in Product Liebility Litigation», Michigan Law Review, 1976, vol. 74, pp. 1.257 y ss.

69 La defensa de una función meramente compensatoria sólo tiene sentido en los estados de Georgia, Connecticut, Michigan y New Hampshire. 
la indemnización $)^{70}$. Pese al reconocimiento de un supuesto propósito compensatorio de estos daños, basándose en los honorarios de los abogados, esto no impide que sigan existiendo como funciones básicas el castigo y la disuasión. Además, como bien apunta Zekoll ${ }^{71}$, los criterios generalmente utilizados en la valoración del quantum de esta partida no son los gastos legales en que incurre el demandado sino la conducta del demandado, su riqueza, la gravedad del comportamiento del agente ilícito, etc. ${ }^{72}$

Por lo tanto, queda claro que los intentos de considerar la función compensatoria como función principal de los daños punitivos no han tenido demasiado éxito. Por ello, se ha buscado otra línea argumental a favor de su reconocimiento, que consiste en la búsqueda dentro del foro de instituciones que también tenga una función penal a pesar de pertenecer al Derecho civil.

Una postura minoritaria ha sido la de encontrar una analogía entre los daños punitivos y los daños por dolor y sufrimiento (Schmerzensgeld) basada en el artículo 847 del Código civil alemán. Se dice que los daños morales en el Derecho alemán cumplen una doble función; por un lado, la función compensatoria, y por otro la función de retribución o castigo $(\text { Genuntuung })^{73}$. Esta analogía no ha sido compartida por la mayoría de los autores, ni tampoco aceptada por los Tribunales. Los Schmerzensgeld se valoran principalmente de acuerdo con la magnitud, gravedad y duración del dolor y el sufrimiento de la víctima, y el Tribunal Supremo alemán ha dejado claro que siempre tienen prioridad los aspectos compensatorios $^{74}$ y que el elemento de castigo es considerablemente menos importante. Es decir, que puede ser considerado como una guía suplementaria, pero no necesaria, para que el tribunal lleve a cabo la valoración del quantum en el caso en particular. La importancia de la función de castigo de los Schmerzensgeld se ve, también, disminuida por el hecho de

70 Sin embargo, como luego veremos, la sentencia del BGH de 4 de julio de 1992 que casó la sentencia del OLG de Düsseldorf, no estuvo de acuerdo con esta interpretación. Para el BGH, la declaración anterior viola la prohibición de revisión del fondo del asunto que rige en materia de reconocimiento y ejecución de sentencias.

71 ZeKoll, «Recognition and Enforcement of American Products...», loc. cit., p. 327.

72 En el Estado de Connecticut la cuantía de los daños punitivos se limita a los gastos del proceso, menos los impuestos. Ver Collens v. New Canaan Water Co., 155 Conn. 477, 234 A2d (1967) y United States Aircraft Corp. v. International Ass'n of Machinists, 161 Conn. 79, 285 A2d 330 (1971). En Texas también se utilizan como criterio para valoración del quantum los honorarios del abogado. Ver, entre otros, Hofer v. Lavender, 679 SW2d 470 (Tex 1984).

73 Vid., BGHZ 18, 149 (1955). El Tribunal tomó este concepto del Derecho suizo, BGHZ 18, 149, en 155 (1955).

74 Vid., ZEKOLL, «Recognition and Enforcement of American Products...», loc. cit., en donde se recoge la sentencia del BGH de 1955 (BGHZ 18, 149, 154). 
que los Tribunales permiten el seguro contra las demandas de Schmerzensgeld ${ }^{75}$, además del hecho de que nunca alcanzan las dimensiones económicas de los daños punitivos norteamericanos ${ }^{76}$.

\section{b) Argumentos en contra}

Fundamentalmente se ha alegado en contra del reconocimiento de los daños punitivos el que la función de castigo y la disuasoria que

75 Durante los últimos 25 años los Tribunales norteamericanos se han enfrentado a la pregunta de si la cobertura de una póliza de responsabilidad civil lo es tanto para los daños compensatorios como para los daños punitivos. En muchas ocasiones, el orden público ha sido el factor que prevalece en la denegación de cobertura. El precedente judicial es el caso Northwestern National Casualty Co. V. McNulty (307 F.2d 432 (5 $5^{\text {th }}$ Cir. 1962)). El Tribunal dijo:

«Cuando una persona es capaz de asegurarse para evitar el castigo gana la libertad de cometer un acto ilícito. No se discute que el seguro contra las multas o las penas viola el orden público. Ese mismo orden público debería invalidar cualquier contrato de seguro en contra del castigo civil que los daños punitivos representan.»

La opinión mayoritaria de la doctrina (Vid. PRIEST, G.L., «Insurability and Punitive damages», Alabama Law Review, 1989, vol. 40, pp. 1.009 y ss.) es que la solución a este problema debería venir de manos de las Compañías aseguradoras. Estas deberían revisar las pólizas y excluir expresamente de cobertura a los daños punitivos. La inactividad de la gran mayoría de las Compañías aseguradoras ha provocado que algunos tribunales las consideren a ellas responsables de la situación y se declaren a favor de la cobertura.

76 REQUEJO ISIDRO, «Reconocimiento en España...», loc. cit., ha recogido la elaboración doctrinal defendida por A. Saravalle para el Derecho italiano. En opinión de Saravalle, la cláusula penal que prevé el pago de una cantidad superior al daño previsible tiene una evidente finalidad disuasoria, aunque no es la única figura del Derecho italiano, ya que también tienen un objetivo semejante «tales como las que se contemplan en el ámbito de las relaciones entre socios (suspensión, exclusión, etc.), originadas en la autonomía privada; o aquellas que resultan de la violación de disposiciones legales y que no se resuelven en un mero resarcimiento. En materia de responsabilidad civil, si bien es prevalente el elemento resarcitorio, existen amplios sectores en los que la determinación del daño a resarcir desarrolla una función de castigo y prevención, como es en el caso de las lesiones a los derechos de la personalidad; y en el ámbito de reconocimiento ante otros foros, señala el autor como especialmente significativo el caso de las astreintes del derecho francés, cuya naturaleza civil no se discute. De todo ello concluye Saravalle que, si bien la finalidad prevalente en la responsabilidad civil es la reparación, existen sectores del Derecho civil en los que el daño a resarcir se determina conjugando ésta con objetivos de sanción y prevención; el argumento de la finalidad penal, como motivo de denegación del reconocimiento de los punitive damages, dejaría de ser válido». Pp. 92-93.

Esta autora también recoge la sentencia del Tribunal de Basilea, de 1 de febrero de 1989, favorable al reconocimiento:

«la naturaleza penal de la institución americana fue excluida atendiendo al fuerte componente resarcitorio de la condena pecuniaria, que servía para contrarrestar el enriquecimiento sin causa del demandado; igualmente se descartó el argumento de contrariedad con el orden público, haciéndose valer una noción atenuada de orden público, por falta de contacto del supuesto con el foro». Pp. 92. 
cumplen es incompatible con los principios del Derecho privado alemán y por lo tanto contraria al 328(1)4 ZPO. El castigo y la disuasión de futuras conductas son mucho más cercanos al Derecho penal que al Derecho civil alemán, ya que en Alemania, al igual que en el resto de los países de Derecho civil ${ }^{77}$, la función principal de la indemnización es la compensación de todos los daños que haya sufrido la víctima del acto ilícito (restitutio in integrum) y, como hemos visto, sólo de una forma muy secundaria y excepcional caben otras funciones (por ejemplo, los Schmerzensgeld). La conclusión de que los daños punitivos sean un castigo para el agente ha llevado a examinarlos bajo los principios de la Constitución alemana. Estos principios, de acuerdo con el 348(1)2 ZPO, son estándares explícitos para determinar el reconocimiento o no de la partida. En particular, los requisitos de certeza (art. 103 II) y prohibición de doble castigo (en bis in idem, art. 103 III), el principio de legalidad y el de certeza de la prueba constituyen axiomas fundamentales de derecho constitucional alemán incompatibles con el reconocimiento de los daños punitivos $^{78}$. El artículo 103 II de la Constitución alemana ha proporcionado

77 La doctrina española también es unánime en la consideración de que el fin de la responsabilidad civil es la reparación del daño causado a la víctima y no el castigo del agente. Vid., entre otros, ANGEl YÁGüEZ, R., Tratado de responsabilidad civil, Madrid, 1993, pp. 49-53.

${ }^{78}$ La posible incompatibilidad de los daños punitivos con la Constitución de los Estados Unidos ha sido uno de los argumentos principales en su contra desde 1986. Han sido cuatro las objeciones constitucionales que se les han hecho. Primero, la objeción de que en estos casos se está violando el principio constitucional de «double jeopardy» o en bis in idem (5th. Amendment, «ninguna persona deberá sufrir dos veces el peligro de un castigo por la misma conducta ofensiva») ya que a una misma persona se la condena por responsabilidad civil y responsabilidad penal por el mismo acto o conducta. Segundo, que las grandes condenas punitivas constituyen un supuesto de «excessive fine» de los prohibidos por la $8^{\text {th }}$ Amendment ( Excessive bail shall not be required, nor excessive fines imposed, nor cruel and unusual punishment inflicted»). En tercer lugar, se ha alegado la contrariedad de los daños punitivos con el principio de «due process» recogido en la $14^{\text {th }}$ Amendment $((\ldots)$ nor shall any State deprive any person of life, liberty or property without due process of law; nor deny any person within its jurisdiction the equal protection of the laws.). Finalmente, se ha dicho que la negativa a condenar a daños punitivos, en ciertos Estados en los casos de muerte discrimina a los demandantes y niega la «equal protection».

El recurso a la prohibición de «double jeopardy» ha dejado de ser utilizado a partir del caso Juzwin v. Amtrong Trading Corp. (1989 WL 19962 (D NJ 1989)). En este caso el demandado volvió a resaltar el paralelismo entre los daños punitivos y las sanciones criminales, fijando la atención en las funciones que subyacen en ambos (castigo y disuasión). Sin embargo, el tribunal mantuvo que a pesar de la cercana analogía entre las sanciones criminales y los daños punitivos, estos últimos no son sanciones criminales y la prohibición de «double jeopardy» está limitada a los procedimientos criminales.

La opinión del Tribunal Supremo de los Estados Unidos sobre la violación de la Octava enmienda ha sido clara y unánime. En Browning-Ferris Industries v. Kelco (845 F 2d 404 
un argumento en contra del reconocimiento, ya que si el fin primario de los daños punitivos es el castigo del agente ilícito, la valoración del castigo se deja al poder discrecional del jurado y, al menos en lo que hace referencia al tamaño de la pena, ésta es demasiado impredecible bajo el artículo 103 II. La indemnización de daños punitivos con un nivel de prueba propio de los procedimientos civiles norteamericanos, «preponderancia de evidencia», conculca también los principios constitucionales alemanes, puesto que si la función de estos daños es el castigo de la víctima se considera que el nivel de prueba debería ser el de los procedimientos criminales, en otras palabras «que no exista ninguna duda razonable».

Otro principio constitucional contrario al reconocimiento es el «principio de proporcionalidad», que también ha sido alegado en contra de ciertas indemnizaciones de pain and suffering, aunque en estos últimos casos sin éxito ${ }^{79}$. Por último, ha sido alegada la violación del principio de igualdad de trato que se produciría entre los acreedores alemanes y los extranjeros en caso de que se admitiese el reconocimiento de la partida de daños punitivos.

Como conclusión, a pesar de que se ha negado la naturaleza criminal de los daños punitivos, han sido sus funciones de castigo y disuasión las que han impedido el reconocimiento de la sentencia por violar el 328(1)4 ZPO.

\section{Comentario a la decisión del Tribunal Federal de Justicia alemán (Bundesgerichtshof), de 4 de junio de 1992, sobre reconocimiento y ejecución de las indemnizaciones norteamericanas de daños punitivos $^{80}$}

La decisión del Bundesgerichtshof, de 4 de junio de 1992, será el objeto de nuestro análisis en las páginas posteriores. Esta decisión, su razonamiento y los hechos sobre los que está basada forman parte de la

(CA2 1988)) el Tribunal negó que una condena de 6 millones de dólares fuese inconstitucional según la Octava enmienda. Declaró que el factor que había inspirado la creación de esta prohibición era limitar la acción del Gobierno (sus posibles abusos) y concluyó que la cláusula no otorga protección a los procedimientos entre particulares.

Tampoco han tenido éxito los recursos de inconstitucionalidad basados en el «due process» y en la «equal protection».

79 Este tema será estudiado dentro del análisis de la sentencia del BGH de 1992.

${ }^{80} \mathrm{La}$ información sobre la sentencia ha sido recogida, en gran medida, de la revista International Legal Materials, «Germany: Federal Court of Justice Decision concerning the recognition and enforcement of U.S. Judgments awarding Punitive Damages», vol. 32, n. ${ }^{\circ} 5$, 1993, pp. 1.320 y ss. (traducción inglesa preparada por Gerhard Wegen y James Sheres). 
práctica de ejecución de sentencias en Alemania y es la única sentencia que existe hasta el momento de un alto tribunal europeo sobre esta materia. El pronunciamiento del Tribunal de Justicia alemán trata no sólo la cuestión de los daños punitivos, sino también otros aspectos del common law y del procedimiento civil norteamericano que se diferencian del Derecho civil y del proceso civil alemán, como son las pruebas pre-trial, los contingency fees, la american rule, y el quantum de las partidas compensatorias.

\section{Los hechos}

Los orígenes del caso se encuentran en Stockon, California, lugar donde residían el demandante y el demandado. Ambos poseían la nacionalidad norteamericana; el demandado además tenía la nacionalidad alemana. En mayo de 1984, el demandado — que había sido sentenciado por un tribunal norteamericano a prisión por abuso sexual de un menor (el demandante) - abandonó los Estados Unidos. Desde ese momento, vivió en Alemania, en donde poseía propiedades.

El Tribunal Superior del Estado de California y del Distrito de San Joaquin, el 24 de abril de 1985, sentenció al demandado a abonar a la víctima una indemnización de 750.260 dólares. De las transcripciones del proceso se desprende que el veredicto estaba basado en la ofensa sexual cometida contra el demandante, quien en el momento de la ofensa tenía 14 años. La indemnización se compone de 260 dólares por gastos médicos pasados, 100.00 dólares por gastos médicos futuros, 50.000 dólares por gastos de colocación de la víctima, 200.000 dólares por ansiedad, dolor, sufrimiento y daños generales de esta naturaleza y 400.00 dólares por daños punitivos. Al abogado de la víctima se le concedió el 40\% (300.104 dólares) del total de la indemnización final recibida por la víctima, como honorarios de abogado.

Ante el Bundesgenchtshof se presenta, en apelación, el reconocimiento y la ejecución de la sentencia del Tribunal Superior del Estado de California.

El Tribunal de Distrito (Landgericht) decidió que en este caso no había impedimento para una orden de ejecución de sentencia más los intereses. En respuesta a la apelación del demandado, el Tribunal de Apelación de Düsseldorf (Oberlandesgencht) ${ }^{81}$ mantuvo la orden de ejecución de la sentencia pero redujo la indemnización a la cantidad de

81 Sentencia del OLG de Düsseldorf, de 19 de febrero de 1992, NJW, 1992, p. 594. 
272.325 dólares. Las dos partes apelaron la sentencia. El Tribunal Federal de Justicia (Bundesgerichtshof) decidió que la cantidad correspondiente a los daños punitivos (400.000 dólares) no podía ser ejecutada en Alemania, sobre el resto de la indemnización se emitió la orden de ejecución.

\section{2. «Pre-trial Discovery»}

En primer lugar se alegó que la sentencia de California era nula y por lo tanto no podía ser objeto de reconocimiento porque el demandado no había recibido una notificación adecuada. El OLG apuntó que existe la presunción inicial de que un acto soberano extranjero es válido, la nulidad debe ser obvia y, por consiguiente, la mera alegación de un defecto, aun cuando sea correcta, no es suficiente para declarar la nulidad del acto. El Alto Tribunal declaró que la falta de notificación no había sido probada y que

«no es labor de los Tribunales alemanes... examinar la compatibilidad de las sentencias norteamericanas con la Constitución de los Estados Unidos y con la Constitución del Estado en particular» ${ }^{82}$.

El demandante, al igual que se había hecho en casos similares, alegó en contra del reconocimiento de la existencia de los "pre-trial discovery». En particular, en este caso se cuestionan las «fishing expedictions ${ }^{83}$ que los «pre-trial discovery» permiten y que no son admitidas en Alemania. Sobre este tema, el alto Tribunal mantuvo la postura del Tribunal de Apelación y de la mayoría de la doctrina, es decir, que este tipo de procedimientos de obtención de pruebas no son, en sí mismos, suficientes para constituir una violación del orden público definido en el 328(1)4 ZPO.

El Tribunal Federal de Justicia alemán consideró que el factor decisivo es el de si el resultado concreto de aplicar estas normas procesales es, en sí mismo, manifiestamente incompatible con los principios esenciales

\footnotetext{
82 (1992) WM en 1454.

83 «Fishing expedictions: Using the courts to find out information beyond the fair scope of the lawsuit. The loose, vague, unfocused questioning of a witness or the overly broad use of the discovery process. Discovery sought on general, loose and vague allegations, or on suspicion, surmise, or vague guesses. The scope of discovery may be restricted by protective orders as provided for by Fed.Rule Civil P. 26(c)». BLACK, H.C., Black's Law Dictionary, St. Paul Minn., West Publishing Co., 1991, p. 440.
} 
del Derecho alemán y con los valores de la investigación judicial. La sentencia determinó que este extremo no había sido probado por los demandados.

«La mera posibilidad de que, entre otras cosas, esta práctica pueda dar lugar a una investigación no permitida bajo las leyes procesales alemanas, no cumple los requisitos del 328, para 1, sub-para 4 del Código de procedimiento civil alemán...

...por lo tanto, no existe base legal sobre la que oponerse al hecho, aceptado por el Tribunal de Apelación, de que el veredicto del Tribunal Superior norteamericano no estaba basado en los procedimientos de "pre-trial discovery"».

\section{3. «Contingent fee»}

Normalmente - la cuestión de los «contingent fees», que se había tratado en los Tribunales alemanes cuando el abogado intentaba cobrarlos en Alemania - suele ser una cuestión que afecta principalmente al demandante y a su abogado. Este caso plantea una particularidad porque los contingent fees aparecen especificados en la sentencia, lo cual es inusual.

La sentencia del Tribunal Superior de California reconocía el derecho del abogado de recibir como honorarios el $40 \%$ del total de la indemnización que reciba la víctima.

Una vez más el Tribunal decidió que la existencia de un acuerdo de «contingent fee» no alcanza el techo necesario para negar la ejecución total de la sentencia norteamericana. Este resultado es particularmente interesante a la luz de la decisión del Tribunal Federal de Justicia alemán de $1963^{84}$, en la que se declaró que tales acuerdos son profesionalmente no éticos y dañan el orden público, al menos en lo que se refiere a los abogados alemanes. Estas dos decisiones diferentes sólo pueden ser reconciliadas si se adopta el punto de vista de que cada jurisdicción tiene que desarrollar su propio sistema legal y el papel de los abogados se tiene que ajustar a ese sistema; en Alemania, el abogado es un oficial independiente del tribunal y no debe ser guiado o motivado por el resultado económico del proceso ${ }^{85}$. La opinión del Tribunal Federal de Justicia alemán es que todos los sistemas legales son libres de determinar las restricciones profesionales que imponen a sus abogados. Ade-

\footnotetext{
84 BGHZ 39, 142 (1963).

85 Vid. «Germany: Federal Court of Justice Decision...», loc. cit., p. 1.323.
} 
más, puso el acento en que la investigación de orden público en el contexto de reconocimiento de sentencias está basada en el 328(1)4 ZPO y no en el artículo 6 EGBGB ${ }^{86}$.

Por último, el Alto Tribunal alemán analizó la aplicación de la «American rule». El Tribunal Federal de Justicia dijo:

«Contrariamente a la interpretación dada en algunas comarcas, no existe una objeción general para el reconocimiento de las sentencias civiles norteamericanas basándose únicamente en que estas sentencias no disponen, en principio, el reembolso de los costes legales de la parte con éxito.

...la razón principal dada para que los costes legales no sean reembolsados es la necesidad de hacer que el acceso a los tribunales sea más directo, reduciendo el riesgo en términos de costes. También tiene relación con la falta de ayuda legal gratuita, que raramente se encuentra a disposición de las partes del proceso.

Desde el punto de vista alemán, la exclusión, de forma habitual, del reembolso de costes legales en las acciones civiles no infringe ningún derecho constitucional fundamental de las partes o ningún principio básico del derecho. Debe ser aceptado...

De hecho, el resultado de aplicar la "American rule of costs" no grava al demandado en el caso presente».

El demandado, en este caso, resultaría afectado por el acuerdo de honorarios contingentes si dicho acuerdo hubiera tenido una influencia directa en la valoración de la indemnización, pero el Tribunal alemán juzgó que este extremo no había sido probado. Aun en el supuesto de que los honorarios hubieran sido tenidos en cuenta, por el Tribunal de California, en la valoración económica de otras partidas compensatorias; este hecho, desde el punto de vista del Tribunal alemán, no constituiría un resultado inaceptable, ya que si el demandante hubiese entablado su acción en Alemania se habría visto obligado a indemnizar a la víctima sus costes legales ${ }^{87}$. El Tribunal dejó la puerta abierta a la aplicación del 328(1)4 ZPO en circustancias en las que el demandado tenga que pagar

«(...) mucho más por "daños compensatorios" de lo que habría sido necesario para compensar por los daños realmente sufridos, incluyendo la cantidad apropiada para los costes legales ${ }^{88}$.

86 (1992) WM en 1459. Vid. explicación anterior sobre la aplicación del artículo 6 EGBGB.

87 1992) WM en 1459.

88 (1992) WM en 1460. 
El Bundesgerichtshof también analizó la cuantía del acuerdo contingente. El Tribunal Superior de California justificó el honorario, expresamente, basándose en la complejidad y la dificultad del proceso en cuestión. El Tribunal Federal de Justicia llegó a la conclusión de que el nivel de honorarios contingentes del abogado en el caso presente no evitaba tampoco el reconocimiento de la sentencia norteamericana.

\section{Indemnización de daños compensatorios excesiva bajo los criterios del país}

El nivel de la indemnización compensatoria concedida en la sentencia norteamericana fue también una de las cuestiones alegadas para impedir el reconocimiento, ya que éste era mayor que el de las indemnizaciones que se conceden en los tribunales del foro.

La apelación hacía referencia, en especial, a la parte de la indemnización que correspondió a los gastos por tratamientos médicos futuros, ya que la víctima no había hecho ningún intento de someterse al tratamiento prescrito, a la fecha del juicio, ni pareció que se fuese a someter a éste después del juicio. En principio, conforme al Derecho alemán, dichos gastos no serían compensados.

El Bundesgerichtshof llegó a la conclusión de que el solo hecho de que un tribunal extranjero llegue a un resultado diferente no supone que el resultado sea inadmisible y se aplique el 328 del Código de procedimiento civil alemán.

El Tribunal de Apelación negó que se estuviera infringiendo el orden público por el hecho de que el Tribunal Superior de California indemnizara a la víctima con 100.000 dólares por tratamiento psicológico futuro y 50.000 dólares por los costes futuros asociados con la colocación, independientemente de si la víctima decidía someterse al tratamiento prescrito. El Tribunal Superior, después de escuchar a los expertos, juzgó que un tratamiento médico del tipo descrito en la sentencia norteamericana, y los cambios relacionados con él, eran objetivamente necesarios, y consideró decisivo el hecho de que, en casos excepcionales, el sistema legal alemán permite la compensación de costes de reparación «ficticios».

«No puede surgir objeción legal alguna a esta conclusión. La apelación es correcta en su aserción de que el Derecho alemán de daños no da a la parte lesionada, en un caso de lesiones a la persona - a diferencia de los supuestos de lesiones a la propiedad - la oportunidad de decidir si desea o no utilizar la cantidad indemnizatoria para reparar el 
daño; y que la parte lesionada no puede, por lo tanto, pedir indemnización por costes "ficticios" de tratamiento (BGHZ, 97, 14, 18 ff.). Sin embargo, lo anterior no evita que el veredicto del Tribunal Supremo sea reconocido.» ${ }^{89}$

El demandado invocó el artículo 328(1)4 del Código de procedimiento civil alemán, a lo que el Bundesgerichtshof contestó que este artículo no impide que se reconozca el veredicto en este supuesto en particular. Para el Tribunal, el que el juez alemán — si hubiera tenido que tomar la decisión - habría — por aplicación del Derecho alemánllegado a una conclusión diferente de la alcanzada por el tribunal extranjero, no significa que un veredicto extranjero sea incompatible con el orden público. Lo decisivo es si el resultado concreto de aplicar una ley extranjera entra en conflicto de forma grave con los conceptos fundamentales de la legislación alemana y con la noción de justicia contenida dentro de ellos, de tal forma que lo convierte en intolerable según las nociones del país ${ }^{90}$.

Dentro de los términos del 328(1)4 del Código de procedimiento civil alemán, cabe la posibilidad de que la parte lesionada reclame una indemnización de daños por gastos médicos sin que actualmente intente someterse a dicho tratamiento médico. La interpretación correcta es la de entender que, aunque dentro del Derecho alemán no se establece ninguna libertad de decisión, la indemnización de lesiones físicas y mentales, que no pueden ser tratadas, y que por lo tanto al final van a convertirse en lesiones permanentes, constituirá de hecho una compensación por incapacidad permanente de salud.

Es sobre esta base sobre la que el Tribunal Superior de California indemnizó a la víctima los costes médicos futuros; por lo tanto estos daños, en las mismas circunstancias, también habrían sido indemnizados en Alemania. El hecho de que la víctima reciba la compensación antes de que realmente incurra en el gasto resulta en una diferencia sistemática entre el Derecho alemán y el norteamericano, que se basa en que el sistema de los Estados Unidos requiere un único procedimiento para la determinación de todas las demandas.

De esta decisión se desprende que el techo es alto a la hora de aplicar la provisión del 328(1) No. 4 del Código de procedimiento civil alemán. Una mera diferencia con el método que se aplica en Alemania se engloba bien dentro de las diferencias aceptables, aun cuando

89 (1992) WM en 1459.

90 Vid. Sentencia, de 21 de enero de 1991, II ZR 50/90, NJW 1991, 1418, 1420. 
produzca un resultado en cierta medida incongruente con la indemnización otorgada si la demanda se hubiese llevado a cabo en Alemania, y aunque incite a que las demandas se entablen en las jurisdicciones más favorables, en lugar de plantearlas en Alemania.

En conclusión, la indemnización de 100.000 dólares por tratamiento médico futuro y de 50.000 dólares por gastos futuros de colocación no daña al orden público alemán y por lo tanto se debe reconocer y ejecutar la sentencia en este extremo.

También fue negada la aplicación del artículo 38 EGBGB al reconocimiento de sentencias y, en opinión del Tribunal, la revisión de 1986 del Derecho alemán sobre ley aplicable demostraba un intento legislativo de separar el reconocimiento de sentencias del análisis de la ley aplicable ${ }^{91}$.

\section{Daños punitivos}

En este caso, el Tribunal federal de Justicia decidió que la indemnización de daños punitivos constituía un ataque al orden público sustantivo conforme al 328(1) No. 4 del Código de procedimiento civil alemán.

En la sentencia del Tribunal Superior de California se indemnizó a la víctima con 400.000 dólares por daños punitivos. El Tribunal de Distrito alemán (Landgericht) decidió que cabía la orden de ejecución sobre todo el veredicto del Tribunal Superior más los intereses. Tras la apelación del demandado, el Tribunal de Apelación de Düsseldorf (Oberlandesgericht) sostuvo la orden de ejecución en la cantidad de 275.325 dólares y anuló el resto. La interpretación del Oberlandesgericht, sobre esta cuestión, fue que la orden de ejecución sólo podía ser emitida sobre la suma requerida para cubrir los costes legales, aunque dicha suma estaba supeditada al examen del orden público. El examen de orden público tuvo como resultado que en lugar del $40 \%$ de la indemnización total que estableció el Tribunal Superior de California como honorarios de abogado, sólo se reconociese el $25 \%$ de la indemnización de daños compensatorios recibida por la víctima (55.065 dólares).

Sin embargo, el Tribunal Federal declaró que las argumentaciones anteriores no eran lo suficientemente convincentes como para invalidar los argumentos del demandado en la apelación. Manifestó que un veredicto norteamericano en el que se indemniza una suma global por daños

91 (1992) WM en 1458. 
punitivos además de una indemnización por daños patrimoniales y extrapatrimoniales no puede, como regla general, ser ejecutado en Alemania.

La sentencia, en primer lugar, realiza un examen de los daños punitivos en los Estados Unidos.

«Los "Punitive or exemplary damages" son, conforme al derecho de la mayoría de los Estados norteamericanos -incluido California-, indemnizados como una suma adicional a aquella requerida para reparar el daño causado, si el agente ilícito ha actuado premeditada, maliciosa, o negligentemente... La imposición de estos daños pertenece, de forma general, al ámbito discrecional del tribunal... La imposición de estos daños sirve a cuatro propósitos principales...»

El Tribunal describe, de forma breve, la función de castigo, la función de disuadir al agente y al público en general de incurrir en el futuro en conductas nocivas para la sociedad, la necesidad de recompensar a la víctima por ejecutar la ley, y finalmente la necesidad de compensar a la víctima por daños que no le son compensados en las otras partidas indemnizatorias (por ejemplo, los costes legales).

«El nivel de la indemnización está gobernado por el poder discrecional del tribunal, el cual, de forma habitual, toma en consideración la naturaleza del acto ilícito, la forma y la gravedad del perjuicio causado a la víctima, pero también el estatus financiero del agente ilícito. En algunos casos, la indemnización se calcula como un múltiplo de la indemnización compensatoria. En otras ocasiones, la indemnización concedida por "pain and suffering" no se indemniza de forma separada de la partida de daños punitivos - contrariamente a lo que ocurre en el caso presente-... En algunos casos ni tan siquiera la indemnización por pérdida de salarios se indemniza de forma separada.»

El Bundesgerichtshof analizó también la naturaleza civil o criminal de los daños punitivos.

«En el Derecho norteamericano, los "punitive damages" forman parte del Derecho civil, independiente de la función punitiva o disuasoria que intentan cumplir. El Tribunal Supremo de los Estados Unidos negó la alegación de que estos daños violaban la prohibición de doble castigo sobre estas bases. Lo mismo se aplica desde el punto de vista alemán... En este sentido, los "punitive damages" fundamentalmente representan una forma especial de indemnización entre individuos privados, sin tener en cuenta las intenciones, en términos de política legal, 
que subyacen en dichas indemnizaciones... En cualquier caso, si — como ocurre en el supuesto presente- la indemnización debe abonarse a la víctima, la cuestión es civil.

La cuestión de si se debe adoptar un punto de vista diferente si los "punitive damages" son abonados al Estado o a otra institución no tiene que ser aclarada.» ${ }^{92}$

Está de acuerdo con la doctrina mayoritaria sobre la naturaleza civil de esta partida indemnizatoria. Por un lado, confirma la posición del Tribunal de Munich, de 15 de julio de $1992^{93}$, y por otro, deja la puerta abierta a que alguna indemnización de daños punitivos pueda ser reconocida en Alemania si su función es compensatoria.

Posteriormente, el Tribunal conoció la cuestión del orden público de acuerdo con el 723, para. 2.2 y 328(1)4 del ZPO alemán, que a la postre sería la cuestión determinante en la resolución de este caso.

«El moderno Derecho civil alemán estipula la compensación de daños sólo como la consecuencia legal de un acto ilícito (249 ff. del Código civil alemán); no dispone el enriquecimiento de la parte lesionada... Lo anterior se aplica tanto si la reclamación de indemnización se defiende ante un tribunal civil como si se defiende ante un tribunal criminal en los procedimientos suplementarios (403 ff. de Procedimiento Criminal). El castigo y la disuasión son fines posibles de la sanción criminal (46 f. del Código penal), bajo la forma de una multa que se paga al Estado, y no fines del Derecho civil.

La concesión a la víctima, como demandante, de un beneficio puede ser explicada gracias a una interpretación del Derecho privado como reglas que tienen, generalmente, un efecto preventivo. El individuo, como "fiscal privado", ocupa el lugar del Estado. Esto es incompatible, conforme a la interpretación legal alemana, con el monopolio estatal de castigo y las garantías procesales especiales que dicho monopolio acarrea. El Derecho alemán contiene en su Derecho civil... ciertas estipulaciones de castigo. Sin embargo, las estipulaciones requieren un acuerdo legal entre las partes y por lo tanto no son relevantes para los principios alemanes de responsabilidad civil.»

A continuación el Tribunal compara las funciones punitivas y disuasorias con la función de satisfacción que rige en la valoración del pain and suffering en Alemania. El término «satisfacción»(Genugtuungs) no tiene un significado fijo. Puede ser entendido en un sentido

92 (1992) WM en 1461.

93 (1992) WM en 1465. 
amplio y aplicarse como reparación de los detrimentos no económicos sufridos por la víctima. Este uso del término descansa en la asunción de que sólo las pérdidas económicas pueden ser compensadas. En Alemania, la noción de satisfacción se utiliza en un sentido más específico. Su propósito es describir la función de la responsabilidad que pretende mitigar la violación del sentido de justicia de la parte agraviada mediante la reacción legal hacia el ilícito. El propósito de la satisfacción ha estado siempre muy relacionado con la institución de castigo pero, en opinión de ciertos autores alemanes, la satisfacción se diferencia del castigo en que la primera se dirige a la parte lesionada y no al agente ilícito. Con el desarrollo del castigo público y el reconocimiento del monopolio estatal sobre las sanciones, las penas privadas se eliminaron en gran medida. Sin embargo, el castigo público impuesto sobre el agente ilícito no siempre parece suficiente para afrontar la satisfacción de la parte agraviada. Por ejemplo IHERING, en un memorándum publicado en 1880, subrayó «la satisfacción por la violación del sentido de justicia» como un objetivo independiente del derecho privado de responsabilidad, junto con los objetivos de castigo y de compensación ${ }^{94}$. La interpretación de Ihering sobre el término «satisfacción» fue aplicada en los Tribunales alemanes en relación con las indemnizaciones de daños morales. Sin embargo, la doctrina legal alemana reciente utiliza el término para designar el objetivo específico de mitigar la violación del sentido de justicia de la víctima.

«La función punitiva y disuasoria de los "daños punitivos", de acuerdo con su interpretación en los Estados Unidos, se justifica a partir del interés público, y no puede ser comparada con la función de satisfacción que debe ser tomada en cuenta, conforme a las líneas nacionales para la valoración de la indemnización, al 847 del Código civil alemán, y a las invasiones de la intimidad. Por un lado, no es la función de satisfacción el factor principal en la valoración de los daños, sino que la atención se debe fijar en el nivel y en la gravedad del daño a la vida (el grado y la duración del dolor, del sufrimiento y de la deformación), mientras que la importancia relativa de otras circunstancias depende del caso en particular (ver BGH, sentencia del 3 de noviembre, 1959 - VI ZR 193/58, VersR 1960, 252, 253). Por otro lado, la función de satisfacción no es suficiente para justificar el carácter penal de la indemnización. (BGHZ 18, 149, 155.) La función de satisfacción está intrínsecamente unida a la función de compensación, la cual es inherente a la

94 Citado en Stooll, H., «Consecuences of Liability: Remedies», International Encyclopedia of Comparative Law, 1975, tomo XX.2., pp. 10. 
demanda de indemnización (BGH, sentencia de 6 de diciembre, 1960 VI ZR 73/60, VersR 1961, 164 f.) y expresa una cierta relación personal entre el agente ilícito y la parte lesionada; dicha relación se inició por el hecho de que se causó un daño (BGHZ 18, 149, 157). Este hecho no cambia, aun si, en un caso individual, el hincapié en la valoración de los daños se coloca sobre la función de satisfacción, porque sólo es posible realizar enmiendas simbólicas para compensar por los daños no materiales.» ${ }^{95}$

La pregunta a la que intenta contestar el Tribunal es si los daños punitivos pueden ser asimilados a la indemnización de daños morales que se concede en el Derecho alemán de acuerdo con la función de satisfacción. En otras palabras, si la indemnización punitiva intenta compensar por los daños extrapatrimoniales sufridos por la víctima.

«En el caso en cuestión, han sido cubiertos (los daños extrapatrimoniales) por una compensación separada de "pain and suffering”. Aún en el supuesto de que se dé plena consideración al hecho - de acuerdo con la alegación hecha por el demandante-de que la salud física tiene una considerable importancia en los Estados Unidos, no parece que exista base alguna para una demanda de satisfacción por encima de lo ya concedido.»

El Tribunal pasa a analizar la posibilidad de que la partida indemnizatoria de daños punitivos intente cubrir los costes legales en los que ha incurrido la víctima.

«Ni la sentencia ni las transcripciones del Tribunal Superior contienen información fehaciente sobre si los "punitive damages" fueron indemnizados con la intención de cubrir todos los costes legales en los que incurrió el demandante. La proporción del 40\%, concedida al abogado como remuneración, se aplica a todas las partidas de la indemnización que realmente se abonen, sin tener en cuenta su clasificación legal. Las cantidades concedidas como compensación por gastos médicos y las que corresponden a "pain and suffering" no han sido calculadas de forma tan precisa como para excluir la posibilidad de que en ellas se incluya un componente que corresponda a los costes legales.

El Tribunal de Apelación no indagó, en términos objetivos, las consideraciones que condujeron al Tribunal Superior en su decisión en relación con los "punitive damages" en el caso presente... 
No hay estadísticas disponibles sobre la frecuencia con la que los Tribunales norteamericanos intentan, entre otras cosas, indemnizar al demandante por todos sus costes legales con la indemnización de daños... En antiguas publicaciones, ni siquiera se menciona este motivo... De hecho, aún en los casos más recientes, este motivo sólo se menciona en circunstancias excepcionales...

Si el propio tribunal extranjero no aporta una información clara y comprensible, el tribunal alemán que es responsable de la orden de ejecución está inhabilitado para valorar los motivos reales de cada caso individual. Como se ha establecido, una indemnización norteamericana de esta naturaleza puede basarse legítimamente en distintos motivos, que pueden ser tratados de forma individual o junto con otros. Para lograr una mejor visión del contenido del veredicto que la que se ha dado hasta ahora, el juez local debería, en la medida de lo posible, tomar el lugar del juez extranjero.

El 723, para.1 del Código de procedimiento civil alemán establece que el juez alemán no tiene derecho a hacer esto. Dichas consideraciones sobre el veredicto estarían basadas, en gran medida, en conjeturas y pondrían en riesgo la certidumbre del derecho.

El Senado tampoco considera permisible utilizar, como base para un veredicto extranjero, el escenario imaginable más favorable para su reconocimiento...»96

El Tribunal vuelve sobre el tema inicial de las funciones de los daños punitivos, o de sus elementos más característicos, para de esta forma poder compararlos con los principios que sobre responsabilidad extracontractual rigen en el Derecho alemán.

«Desde este punto de vista, los daños punitivos norteamericanos están caracterizados por los elementos de castigo y disuasión... Históricamente, es sobre estos elementos sobre los que se han basado los daños punitivos...; aún hoy, estos elementos todavía desempeñan un papel habitual en la valoración de los daños... La alegación de culpa es la cuestión crucial. La reducción del acento puesto sobre los intereses privados ilustra el hecho de que la parte lesionada no tiene una reclamación legal. Y, además, como no hay una relación general clara entre las sumas a determinar y el daño sufrido, la cuestión de la compensación tiene normalmente una importancia menor.»

\footnotetext{
96 Para HAY, «The Recognition and Enforcement of American...», loc. cit., p. 747, esta conclusión no está clara, no parece muy consistente negar la posible inclusión de los costes legales en la partida de daños punitivos por ser muy especulativa en la base, también especulativa, de que estos gastos podrían estar incluidos como parte de lo que el tribunal extranjero denominó «compensación».
} 
Por todo lo anterior, el Tribunal considera que una indemnización de daños punitivos no puede ser ejecutada en Alemania porque es incompatible con los principios fundamentales del Derecho alemán.

«Uno de los principios fundamentales del Derecho alemán es el principio de "proporcionalidad", el cual surge del estado constitucional y es válido también en el Derecho civil... En el Derecho civil, la atención que se presta a la compensación en la valoración de los daños, entre otras cosas, tiene este principio en cuenta; a menudo, la única intención apropiada de la acción civil, tomada en respuesta a un acto ilícito, es la de compensar por los efectos de ese acto sobre las circunstancias financieras de las partes directamente afectadas. Las reglas de procedimiento y las reglas sobre la prueba para las acciones de esta clase permiten a las partes ejercer una influencia variada y dominante sobre el resultado, y han sido diseñadas con este propósito. Las acciones civiles norteamericanas están gobernadas por reglas similares...

Las sanciones que intentan ser punitivas o disuasorias $-\mathrm{o}$, por ejemplo, proteger el derecho y el orden público- son, según la interpretación alemana del derecho, parte del monopolio de castigo ejercido por el Estado. Es él quien ejercita este monopolio en interés del público en un proceso especial, en el que por un lado la investigación oficial intenta proveer de una mejor garantía para que la decisión sustantiva sea exacta, mientras que por otro lado asegura una mayor protección para los derechos del demandado. Desde un punto de vista local, sería inaceptable imponer, en un juicio civil, el pago de una considerable suma de dinero, la cual no intenta ser compensación por los daños, sino que es calculada esencialmente según el interés público y puede ser impuesta junto con el castigo criminal por la misma ofensa...

De hecho, esto es lo que ha ocurrido en el caso presente. La indemnización impuesta es mayor que el total de todas las sumas concedidas para compensar por el daño causado. Aun el total de todos los costes legales supondría sólo una tercera parte de los "daños punitivos". No existe prueba de otros daños por los que se deba conceder compensación. El efecto de la orden de ejecución en el demandado sería, por lo tanto, excesivo.

Los daños punitivos impuestos bajo el poder discrecional del tribunal, los cuales no tienen una relación firme con el daño sufrido y algunos de los cuales son extremadamente altos, han contribuido a un importante aumento en la carga de las indemnizaciones en la economía como un todo. Dicha carga ha alcanzado ahora el límite del riesgo calculable y asegurable...

...Por esta razón, la ejecución de una reclamación de indemnización por daños - superior a la compensación de todas las lesiones patrimoniales y extrapatrimoniales realmente sufridas - constituiría en sí misma un resultado inaceptable... 
La ejecución en Alemania está, por lo tanto, excluida. No es necesario determinar si la ejecución de la indemnización de daños también contraviene la ley y el orden alemán en otras bases. En particular, no hay necesidad de determinar si las condiciones para la imposición de un veredicto de daños punitivos, cuyas condiciones son difíciles de estipular, y la cantidad de la indemnización deben valorarse según las bases del artículo 103, para.2 (Derechos constitucionales en el tribunal) de la Constitución de Alemania, o si la condena a este pago, así como la pena criminal, constituiría, desde el punto de vista alemán, una violación de la prohibición de castigo múltiple (art.103, para.3 de la Constitución alemana).»

\section{Reconocimiento parcial}

El Tribunal reconoce que no existe impedimento para emitir una orden de reconocimiento y ejecución parcial sobre una sentencia. El Tribunal podía haber negado el reconocimiento total de la sentencia basándose en que la indemnización de daños punitivos es una unidad indivisible bajo el Derecho norteamericano y por lo tanto cualquier reducción supondría una modificación de la decisión extranjera y violaría la prohibición de revisión del fondo del asunto (723.1 ZPO) ${ }^{97}$. Sin embargo, este argumento no ha recibido el apoyo ni de la jurisprudencia ni de la doctrina alemanas ${ }^{98}$.

«El hecho de que el fallo del Tribunal Superior no pueda ser ejecutado en Alemania porque impone daños punitivos no significa que el resto de la sentencia no sea reconocido.

Contrariamente a la opinión expresada en la apelación, el hecho de que la cuestión en disputa en la ejecución sea, no la demanda sustantiva sobre la que el título extranjero está basada, sino que está determinada por el deseo del acreedor de hacer que el título sea ejecutable en Alemania, no significa que una única decisión tenga que emitirse siempre sobre la orden de ejecución por la suma total indemnizada en la sentencia extranjera. En casos en los que un único veredicto extranjero trata demandas distintas e independientes, cada una de ellas puede ser investigada de forma individual, para de esta forma ver si cumple con las condiciones para el reconocimiento.

Si algunas de las demandas no cumplen con el orden público, es posible el reconocimiento parcial; el demandante no tiene por qué tenerlo

\footnotetext{
97 Esta fue la postura del Landgericht de Berlín (1989).

98 Vid. STIEFEL, STÜRNER, STADLER, «The Enforceability of Excessive...», p. 798.
} 
en cuenta a la hora de plantear su petición. Como consecuencia, no existe base para oponerse al hecho de que el Tribunal de Apelación sometió a una inspección separada de orden público a las partidas del veredicto del Tribunal Superior correspondientes a los costes médicos pasados y futuros o costes de colocación, los daños morales y los daños punitivos.»

\section{Conclusión}

El Derecho alemán de daños, al igual que el Derecho español, se rige por el principio de "restitutio in integrum», bajo el cual, en teoría, serán compensadas todas las pérdidas sufridas por la víctima de un acto ilícito. Este principio no recoge el enriquecimiento de la víctima, más bien lo excluye. Como hemos visto, los daños punitivos dan lugar a un enriquecimiento contrario al principio anterior. Además, el Derecho privado continental no permite que la víctima actúe como un fiscal privado y por ello también los daños punitivos podrían ser contrarios al orden público.

De la exposición anterior podemos deducir que no hay problemas para considerar la naturaleza civil de los daños punitivos, que el análisis de si se busca con su indemnización el abono a la víctima de los costes de honorarios se ve impedido por la prohibición de revisar el fondo del asunto, que no existen en el Derecho civil alemán instituciones con funciones punitivas que puedan ser asimiladas a la de los daños punitivos y que es su función punitiva la que los hace incompatibles con el orden público alemán, por lo que deja abierta la posibilidad de que si su finalidad fuese compensatoria podrían ser ejecutados en Alemania. Esto último sólo podría ocurrir en demandas que provengan de los Estados que no reconocen una función de castigo ${ }^{99}$, y que sólo reconocen una función compensatoria.

El Tribunal Federal de Justicia alemán podría permitir la ejecución de una sentencia en la que se incluyeran daños punitivos pero en la que se declarase la naturaleza compensatoria de dicha partida. Considero

99 Vid., ReQUeJo IsIDRO, «Reconocimiento en España...», loc. cit., p. 95:

«Es opinión de la doctrina que esta previsión, pese a su carácter progresista, carece de eficacia práctica, en la medida en que la prohibición de revisión de fondo de la sentencia extranjera cuyo reconocimiento se requiere impide al Tribunal alemán la interpretación de los motivos que puedan estar implícitos. Esto quiere decir que en cada sentencia americana de punitive damages tiene que aparecer claramente establecido el sentido compensatorio de los daños, o de cada partida dentro del montante de los mismos: lo que, siendo la cuantía determinada por un jurado, es poco probable.» 
que esto, que a primera vista podría parecer una puerta abierta a la ejecución de daños punitivos en Alemania, en realidad no será tal en la gran mayoría de los casos. La función principal de los daños punitivos, aunque puedan tener una función compensatoria, no es ésta, sino la de castigo del agente ilícito y la disuasoria de posibles conductas similares en el futuro. Sólo en aquellos Estados en los que el Derecho de daños punitivos ha sido reformado por ley y se ha limitado su cantidad a los costes legales sufridos por el demandante podría el tribunal alemán reconocer la ejecución de la sentencia norteamericana. 